\title{
WestVirginiaUniversity
}

THE RESEARCH REPOSITORY @ WVU

Graduate Theses, Dissertations, and Problem Reports

2009

\section{Three essays on political economy, economic *development and capital flows}

\author{
Nabamita Dutta \\ West Virginia University
}

Follow this and additional works at: https://researchrepository.wvu.edu/etd

\section{Recommended Citation}

Dutta, Nabamita, "Three essays on political economy, economic *development and capital flows" (2009). Graduate Theses, Dissertations, and Problem Reports. 4458.

https://researchrepository.wvu.edu/etd/4458

This Dissertation is protected by copyright and/or related rights. It has been brought to you by the The Research Repository @ WVU with permission from the rights-holder(s). You are free to use this Dissertation in any way that is permitted by the copyright and related rights legislation that applies to your use. For other uses you must obtain permission from the rights-holder(s) directly, unless additional rights are indicated by a Creative Commons license in the record and/ or on the work itself. This Dissertation has been accepted for inclusion in WVU Graduate Theses, Dissertations, and Problem Reports collection by an authorized administrator of The Research Repository @ WVU.

For more information, please contact researchrepository@mail.wvu.edu. 


\title{
THREE ESSAYS ON POLITICAL ECONOMY, ECONOMIC DEVELOPMENT AND CAPITAL FLOWS
}

\author{
Nabamita Dutta \\ Dissertation submitted to the \\ College of Business and Economics \\ at West Virginia University in partial \\ fulfillment of the requirements for the degree of \\ Doctor of Philosophy \\ in \\ Economics \\ Santiago Pinto, Ph.D., Chair \\ Ronald Balvers, Ph.D. \\ Alexei Egorov, Ph.D. \\ Peter Leeson, Ph.D. \\ Russell Sobel, Ph.D. \\ Department of Economics \\ Morgantown, West Virginia \\ 2009
}

Keywords: Political Institutions, Development

Copyright 2009 Nabamita Dutta 


\section{Abstract \\ Three Essays on Political Economy, Economic Development and Capital Flows}

\section{Nabamita Dutta}

This dissertation presents three chapters on the role of political institutions in the allocation of assets and on the dynamics in the corporate taxation policies of multinational firms from a political economy perspective. Chapter 2 revisits the role of the political regime on asset returns in an International Capital Asset Pricing Model (CAPM) framework. Chapter 3 explores the linkages between foreign aid and the quality of political institutions of a nation. Chapter 4 adopts a political economy framework and tries to investigate the impacts of taxation policies adopted by the multinationals on domestic welfare of nations.

Chapter 2 titled, Effect of the Political Regime on Asset Returns in Emerging Markets: An Empirical Investigation explores the linkages of political institutions and stock market development of emerging economies. Using a Capital Asset Pricing Model (CAPM) framework and a sample of 17 Emerging countries, the results show that political regimes play a significant role in the average stock return of assets. Democratic institutions provide an environment with secured property rights, lower risks of expropriation by the government, well developed capital markets and favorable investment conditions. The results suggest that better political institutions have a negative relationship with asset return conditional on the fact that the nationalization of assets has not occurred. Firms in autocratic regimes have higher average returns that exceed the required returns which is consistent with the fact that autocratic institutions are more prone to political and financial risks. In CAPM framework average returns equal required returns over a long enough period of time. The fact that the average returns are higher than the required returns in autocratic countries can partly be explained by the fact that the nationalization of the assets, for which investors require insurance premium, had not yet occurred in my sample. An alternative model to the standard CAPM risk model is considered to establish robustness of the results. Additionally, an unbalanced panel of 30 emerging countries is considered. The results are qualitatively identical for all specifications.

How does foreign aid affect recipient countries' political institutions? Chapter 3 titled, The Amplification Effect: Foreign Aid's Impact on Political Institutions tries to find an answer to this question. Two competing hypotheses offer contradictory predictions. The first sees aid, when delivered correctly, as an important means of making politically-centralized recipient countries more democratic. The second sees aid as a corrosive force on recipientcountry political institutions that makes them more dictatorial. Our paper offers a third hypothesis about how aid affects recipients' political institutions we call the "amplification effect." We argue that foreign aid has neither the power to make dictatorships more democratic nor to make democracies more dictatorial. Instead, aid only amplifies the existing political institutions of recipient countries. We investigate this hypothesis using a panel that covers 73 countries between 1975 and 2003. Our findings support the amplification effect. Aid strengthens democracy in already democratic countries and dictatorship in already dictatorial regimes. It does not, however, alter the trajectory of political institutions in democratic or dictatorial recipient nations. 
Chapter 4 titled, The Role of Political Economy in Corporate Taxation explores the impacts of Formula Apportionment (FA) taxation policy, in the presence of a political economy. The specific formula used to allocate profits of multinational firms for tax purposes will affect the firm's incentive to operate in the country. As a result the choice of a particular formula will also end up having an impact on local consumers, local government and the multinational itself. The different formulas assign different weights to the capital, sales and labor shares of the multinational corporation. Suppose that the choice of the formula is the result of a political process. Which formula would then be chosen by governments representing the interests of domestic consumers, which one would be chosen to represent its own interest and which ones would be chosen to represent the interest of the multinational firm? We present a theoretical model that provides rigorous answers to these questions. 


\section{Acknowledgements}

I would like to thank my committee members Santiago Pinto, Ronald Balvers, Alexei Egorov, Peter Leeson and Russell Sobel for their time, precious guidance and belief in my abilities. I will remain immensely grateful to all of them. They have simply been the best.

I would especially like to thank my advisor Dr. Pinto for being a wonderful guide and for being so supportive and caring throughout my Ph.D. I have learnt so much from him.

I would also like to thank Dr. Sobel, who has behind my progress every step of the way - through his advice, encouragement and inspiration.

I shall be ever grateful to Dr. Balvers for being so reachable and supportive whenever I sought his advice on some crucial issues; to Dr. Egorov, for always having time to help me out on the numerous occasions I arrived unannounced at his office and to Dr. Leeson, for starting off my first year at WVU with a fantastic reading course which led to my first research project.

Someone else I would very much like to mention, without whose encouragement and support I would not have been able complete my thesis, is my dear friend Tushar. I would also like to acknowledge the advice and moral support I received from my other friends and colleagues during my years as a graduate student, especially my room-mate, coauthor and fellow conspirator Sanjukta.

Finally, I wish to thank my family and most importantly my parents, my brother and my sister-in-law, who have been a constant source of support and encouragement even from thousands of miles away. 


\section{Dedication}

I would like to dedicate this thesis to my parents. 


\section{Contents}

$\begin{array}{ll}\text { Abstract } & \text { ii }\end{array}$

Acknowledgements

1 Introduction 1

2 Effect of the Political Regime on Asset Returns in Emerging Markets: An $\begin{array}{ll}\text { Empirical Investigation } & 9\end{array}$

1 Introduction . . . . . . . . . . . . . . . . . . . . 9

2 Hypothesis Development . . . . . . . . . . . . . . . . . . . . . 12

3 Data . . . . . . . . . . . . . . . . . . . . . . 15

4 The Regression Framework . . . . . . . . . . . . . . . . . . . 17

$5 \quad$ Using other Proxies for Political Institutions . . . . . . . . . . . . . . . . . 19

6 An Alternative to the Market Risk Factor . . . . . . . . . . . . . . . . 20

7 Robustness . . . . . . . . . . . . . . . . . . . . . . 21

8 Further Testing for Robustness of the Results . . . . . . . . . . . . . 23

9 Controlling for Economic Freedom . . . . . . . . . . . . . . . . . 25

10 Conclusion . . . . . . . . . . . . . . . . . . . . . . 27

3 The Amplification Effect: Foreign Aid's Impact on Political Institutions 34

1 Introduction . . . . . . . . . . . . . . . . . . . . . . . 34

2 The Amplification Effect . . . . . . . . . . . . . . . . . 37

3 Data and Empirical Strategy . . . . . . . . . . . . . . . . . . . . 41

$3.1 \quad$ Data . . . . . . . . . . . . . . . . . . . . . . 41

$3.2 \quad$ Empirical Specification . . . . . . . . . . . . . . . . . . . 42

4 Benchmark Results . . . . . . . . . . . . . . . . . . . . . . 45

4.1 Benchmark Results for Levels . . . . . . . . . . . . . . . . . . . . 45

4.2 Changes in Political Decentralization . . . . . . . . . . . . . . 49

5 Robustness . . . . . . . . . . . . . . . . . . . . 51

6 More Robustness . . . . . . . . . . . . . . . . . . . . . . . . . 52

7 Conclusion . . . . . . . . . . . . . . . . . . . 53

4 Corporate Profit Tax, Formula Apportionment, and Multinational Firms 64

1 Introduction . . . . . . . . . . . . . . . . . . 64

2 The Model . . . . . . . . . . . . . . . . . . . . . . 68 
$2.1 \quad$ Formula Apportionment . . . . . . . . . . . . . . . . . . . 69

2.2 Timing of events . . . . . . . . . . . . . . . . . . . . . . . . . . . . . . . . . .

3 Characterization of the Equilibrium . . . . . . . . . . . . . . 72

$3.1 \quad$ Second Stage: The MNC's Problem . . . . . . . . . . . . . . . 72

$3.2 \quad$ Numerical Example . . . . . . . . . . . . . . . . . . . 75

3.3 First Stage: The Government's Problem . . . . . . . . . . . . . . 76

4 Results . . . . . . . . . . . . . . . . . . 77

4.1 Case $(\mathrm{i}): \theta_{T}^{i}=1 \ldots \ldots \ldots \ldots \ldots \ldots$. . . . . . . . . . . . . . . . . . . . . . . . . .

4.2 Case (ii): $\theta_{C S}^{i}=1 \ldots \ldots \ldots \ldots$. . . . . . . . . . . . . . . . . . . . . . . . . 78

4.3 Case (iii): $\theta_{N}^{i}=1 \ldots \ldots \ldots$. . . . . . . . . . . . . . . . . . . . . . . . . 79

5 Conclusion . . . . . . . . . . . . . . . . . . . . 79

5 Conclusion $\quad 85$

$\begin{array}{lr}\text { Bibliography } & 87\end{array}$ 


\section{List of Figures}

3.1 Aid's Impact on Political Decentralization by Regime Type (Groups of Two $\ldots \ldots \ldots \ldots \ldots \ldots \ldots \ldots \ldots \ldots$

3.2 Aid's Impact on Political Decentralization by Regime Type (Groups

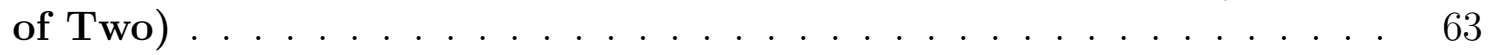

4.1 Tax Revenues in $a$ as a function of $m^{k a}$ for different values of $m^{k b}$. 82

4.2 Consumer Surplus in $a$ as a function of $m^{k a}$ for different values of $m^{k b} 83$

4.3 After-Tax profits in $a$ as a function of $m^{k a}$ for different values of $m^{k b} \quad 84$ 


\section{List of Tables}

$2.1 \quad$ Variables and Sources . . . . . . . . . . . . . . . . . . . . . . . . . . . . . 29

2.2 Overall Summary Statistics . . . . . . . . . . . . . . . . . . 30

2.3 Correlation Matrix of the Polity and the ICRG Variables . . . . . 30

2.4 Second Pass Regressions With Polity, TENSYS and Controlling for Financial Development . . . . . . . . . . . . . . . . . . . . 31

2.5 Second Pass Regressions with Polity, Fama French Factors and Exchange Rate Factors . . . . . . . . . . . . . . . . . . . . . . . . . . 32

2.6 Second Pass Regressions with ICRG variables . . . . . . . . . . . . 33

3.1 The Impact of Foreign Aid on Political Decentralization(Both levels and changes $) \ldots \ldots \ldots \ldots \ldots$. . . . . . . . . . . . . 56

3.2 The Impact of Foreign Aid on Political Decentralization(Both levels and changes $) \ldots \ldots \ldots \ldots \ldots$. . . . . . . . . . . . . 57

3.3 The Impact of Foreign Aid on Political Decentralization(Both levels and changes $) \ldots \ldots \ldots \ldots \ldots$

3.4 With Dummies for Dictatorships . . . . . . . . . . . . . . . 59

3.5 List of Countries . . . . . . . . . . . . . . . . . . . . . 60

3.6 Data Sources . . . . . . . . . . . . . . . . . . . . . . 61

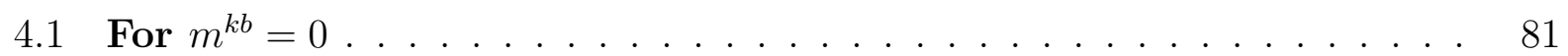

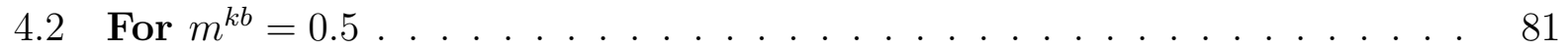

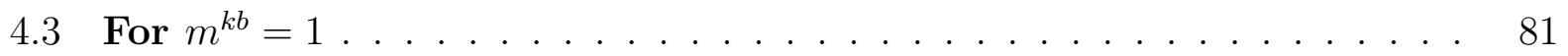




\section{Chapter 1}

\section{Introduction}

What are the factors that determine the burden of taxation for alternative tax bases, the responsiveness of the government towards the economy, the extent and type of public goods provision and the inherent institutional characteristics of an economy? Political economy plays an integral role in each and every sphere of economic activity. The role of political institutions in shaping the development process of nation has been the most significant contribution of the models of political economy. "Why are some countries more developed than the others?" Recently, economists have tried to answer this question with a political economy perspective. The importance of property rights in economic development, the size and composition of government, issues dealing with contracting and information, the role of legal institutions and corporate governance, the downside of corruption and voting behavior are the points of focus for political economy. The typical questions that are addressed in recent research are the relations between democracy and growth, the spill over effects of political institutions, role of political institutions in aid allocation, political barriers to development-enhancing policies, corruption and political instability.

My research mainly encompasses the role of political economy and political institutions in several aspects of economies. The first two essays of my dissertation delve into the connections of political institutions and the allocation of resources in the economy. Specifically, the 
first essay explores the connections between political institutions and average asset returns of emerging market firms. The analysis reveals that there is significant connection between the two. In essay two, the analysis is carried further to investigate the impact of foreign aid on political institutions. The results reveal that foreign aid affects the quality of political institutions of the recipient nations to a significant extent. The third essay investigates the role of political economy in corporate taxation policies of Multinational Corporations.

Chapter 2 titled, "Effect of the Political Regime on Asset Returns in Emerging Markets: An Empirical Investigation," explores the linkages of political institutions and stock market development of emerging economies. Using a Capital Asset Pricing Model (CAPM) framework and a sample a 17 Emerging countries, the results show that political regimes play a significant role in the average stock return of assets. Democratic institutions provide an environment with secured property rights, lower risks of expropriation by the government, well developed capital markets and favorable investment condition. The results suggest that better political institutions have a negative relationship with asset return conditional on the fact that the nationalization of assets has not occurred. Firms in autocratic regimes have higher average returns that exceed the required returns which is consistent with the fact that autocratic institutions are more prone to political and financial risks. In CAPM framework over long enough period of time average returns should be equal to the required returns. The fact that the average returns are higher than the required returns in autocratic countries can partly be explained by the fact that the nationalization of the assets, for which investors require insurance premium, has not yet occurred in my sample.

To the best of my knowledge, this is the first paper exploring the link between political institutions and asset returns. The paper adopts a CAPM framework since it is the most popular models dealing with the determination of expected returns on securities and other financial assets. According to the CAPM theory, investors can earn risk premium or additional expected return if they are willing to undertake more risk. Democratization of an economy has been shown to have substantial impacts on its institutions along with financial markets. 
It expands civil liberties and economic freedom, ensures most efficient allocation of resources and discourages corruption and lawlessness (Olsen 1993; Clague et al, 1996; Minier, 1998; Persson, 2005). Countries controlled by elite groups tend to restrict participation in the political system and protect their own interests. The more the power held by elite groups, the more are the barriers to financial development (Beck et al, 2003). Moreover, better political institutions hikes investments, lead to contract enforcements, smoothens access to external credit and also result in significant financial development for economies (Huang 2005; Rajan and Zingales 2003; Olsen 1993). All these factors create sufficient externalities to affect the average stock return of assets significantly.

The two pass methodology approach has been adopted to test the hypothesis. In the first pass, time series estimates of the individual asset betas are obtained by ordinary least squares (OLS). The second pass regression is conducted on the average return of assets by using the estimated betas from the first pass as independent regressors. Polity, as a proxy for political institutions, is the variable of interest in the paper. The variable ranges from a score of -10 to +10 with a higher value indicating more democratic institutions. The variable seeks to measure the institutional quality of an economy based on the freedom of suffrage, the efficiency of civil and political liberties and the operational constraints on the executive. In the second pass, both the initial polity and the mean polity have been included. Mean polity captures the capital gains or loses over time. The results suggest that initial polity has a significant negative relationship with the average return of assets. Since a lower polity score implies a more autocratic regime, more political, economic and financial risks and, thus, average returns are higher than requires returns. The investors need to be compensated for the higher chances of nationalization. The initial polity proxies for the compensation of nationalizations implying that more autocratic institutions should have higher average returns. The robustness of the findings have been tested by including proxies of political risks like corruption, external and internal conflicts and law and order along with the main variable, polity. Initial polity remains significant for the alternate 
specifications. Further, an alternative model to the standard market risk model has also been used. The findings are robust with the Fama French three factor model. The conclusion also remains unaltered with an alternative proxy of political institutions. Further, to control for the financial institutions of the emerging economies, two alternative proxies of financial development have been included in the specifications. The significance of the coefficients remains unaffected.

How does foreign aid affect recipient countries' political institutions? Chapter 3 titled, "The Amplification Effect: Foreign Aid's Impact on Political Institutions," tries to find an answer to this question. There are two contradictory views about the impact of foreign aid on recipient countries' institutions. According to one view, foreign aid has sufficient capacity to transform the political institutions of the developing countries for the better. Foreign aid provides the support to strengthen judiciaries and legislatures (Knack 2004), improves education and income and promotes democracy in recipient nations through conditionality. The pessimistic view about foreign aid is that such assistance can be detrimental for the political institutions of the recipient nations. Instead of promoting democracy, foreign can actually corrode the quality of institutions for the developing countries. Foreign aid flows to countries generate a windfall of resources. This allows the corrupt rulers to exploit their political powers by gaining substantial control over resources. Our paper presents a third, hybrid hypothesis called the "amplification effect". This hypothesis claims that foreign aid neither causes democracies to become more dictatorial nor causes dictatorships to become more democratic. Foreign aid amplifies recipients' existing political institutions rather than fundamentally changing them.

We investigate our hypothesis using panel data for 73 developing countries between 1975 and 2003. The two stage least squares (2SLS) results confirm our hypothesis. We have examined several specifications to strengthen our hypothesis. Aid received by a country in one period affects the political institutions in the same period. But this impact is conditional on the extent of democracy/ dictatorship in its political institutions in the previous period. 
In order to examine this hypothesis, we need to construct an interaction term consisting of aid received by a country in time $t$ with its political institutions in time t-1 to predict our dependant variable, political institution in t. We adopt a two stage least squares approach by instrumenting foreign aid. The regression specification is as follows

The interaction term is positive and significant which confirms our hypothesis. In fact, is it possible to define a critical democracy/ dictatorship value from the specification, at which aid exerts no impact on recipient political decentralization. The critical democracy/dictatorship is remarkably close to zero. Countries that are more democratic than the critical level become more democratic with additional foreign aid. Similarly, countries with a score lower than the critical score will tend to become more dictatorial with additional aid.

The amplification effect is, further, examined by decomposing the institutions into subgroups that correspond to the strength of democracy/dictatorship. This allows us to study the effect of aid more explicitly. By doing this, we are able to see whether the amplification effect identified in previous specification is true for all levels of democracy/dictatorship. The findings not only support this, but also reconfirms that the tipping point of aid's direction of effect on recipient political decentralization is close to zero. The hypothesis is, further, tested by decomposing the effect into smaller subgroups to capture the effect of aid on recipients' political decentralization in a more detailed manner. Our results are robust with both levels of political decentralization and changes in political decentralization as dependant variables. With changes in political decentralization as the dependant variable, the critical political decentralization value stays the same, close to zero.

To add to the robustness of the results, we rerun our main specification with a simple dummy for dictatorships, any country with a negative political decentralization score. For both levels and changes in political decentralization, additional foreign aid worsens the quality of political institution and makes a country more dictatorial. The results are robust to the inclusion of additional control variable, illiteracy and an alternative measure of foreign 
aid, aid per capita. With aid per capita, the results change slightly but remain fundamentally similar. Finally, we check our results to the sensitivity of the sample period. For both the panels, 1970 - 2003 and 1965 - 2003, the critical political decentralization value remains close to zero and it is reconfirmed that foreign aid makes dictatorships' institutions more dictatorial and democracy's institutions more democratic.

Chapter 4 titled, "The Role of Political Economy in Corporate Taxation," explores the impacts of the taxation policy, Formula Apportionment (FA), in the presence of a political economy. When a corporation has business activities established in multiple countries, the local authority can levy a tax on income generated on that location. But measuring the income earned within each region is a difficult conceptual issue. For instance, the corporate taxation in the European Union requires firms to maintain different accounts for its activities in each country where it operates. This system is called separate accounting (SA) where the subsidiaries act as distinct companies in the multiple locations. The US and Canada, on the other hand, use a formula apportionment (FA) system which has been the focus of recent research. FA, as used in the US, asserts that the proportion of a multi-regional firm's income earned in a given state is a weighted average of the proportion of the firm's total sales, property, and payroll in that state. Thus, the firm's activities in a specific region are approximated by the share of these factors in the region. In other words, the firm is not required to keep different account. A key difference between FA and SA is that former curbs the incentives of the firms to engage in transfer pricing.

In this paper, we examine how political factors may shape the structure of the corporate profit tax in the presence of multinational corporations. There is a huge array of literature which tries to explore the advantages and disadvantages of SA and FA in terms of optimizing the objectives of corporate taxation policies. Yet, no study has explored the question that how the incentives of a multinational firm to operate in a location change when the local government tries to maximize the domestic welfare. In the case of Formula Apportionment regime, the specific formula used to allocate profits of multinational firms for tax purposes 
will affect the firm's incentive to operate in the country. As a result the choice of a particular formula will also end up having an impact on local consumers, local government and the multinational itself. The different formulas assign different weights to the capital, sales and labor shares of the multinational corporation. Suppose that the choice of the formula is the result of a political process. Which formula would then be chosen by governments representing the interests of domestic consumers, which one would be chosen to represent its own interest and which ones would be chosen to represent the interest of the multinational firm?

The governments in respective locations will have the objective to maximize tax revenues, consumer surplus or after tax-profits of the multinational firm. Accordingly as the objectives are chosen, the appropriate formula based on sales and capital shares will be selected. The weight attached to the welfare of each of the three groups - the consumers, the government or the bureaucracy or the multinational firm - will depend on which group gets more importance in relation to the other two. The weight will, thus, be dependent on the extent of political influence of each group to lobby for its welfare. If, for example, the consumers or the populace can lobby for its welfare to the government to a great extent, then the weight allocated to consumer surplus will be the maximum. Accordingly as the particular formula is chosen, the multinational firm will respond by choosing the amount of capital allocation in each location. For example, if the government wants to maximize the sum of consumer surplus in countries, then it will accordingly select the optimal formula for taxing the multinational firm and then based on that decision the firm, in turn, will select the amount of capital allocation which optimizes their profits. Multinational firms have the option of shifting profit from one jurisdiction to another so as to minimize their overall tax payments and, thus, to maximize their profits. If capital is taxed heavily in one location, the multinational will prefer that capital should be taxed relatively less in the other so that it can shift its production from one location to the other.

We consider a model where multinational corporation (MNC) has activities in both coun- 
tries. The MNC in both locations produce the same good and it can transfer (at a cost) part of its production from one country and sell it in the other. Suppose that both regions adopt a formula apportionment (FA) method to calculate the share of the firms activities in each jurisdiction. We examine the incentives of domestic governments to choose different FA systems. In doing so, it is assumed that domestic governments decide the formula system non-cooperatively. Additionally, we focus on a partially symmetric equilibrium. We use the notion of Sub-game Perfect Nash equilibrium, which means that we solve the game by backward induction. We begin by studying the response of the MNC in the second stage of the game to different FA systems. The results show that when governments want to maximize domestic tax revenue, the equilibrium FA system would give full weight to sales portion of the formula. The equilibrium FA system would give full weight to the capital portion of the formula when governments want to maximize consumer surplus. Finally, when the government wants to maximize the after-tax profits of multinational firm, then both capital and sales can be taxed high or low. 


\section{Chapter 2}

\section{Effect of the Political Regime on}

\section{Asset Returns in Emerging Markets:}

\section{An Empirical Investigation}

\section{Introduction}

Institutional quality is a major determinant of the overall development of an economy. Institutions have been defined by economist like Douglas North as the 'essential constraints' binding the society. To quote North (1991), "Institutions are humanly devised constraints that shape human action". A growing number of studies have stressed the importance of institutions in protecting property rights and boosting investment for an economy. Some of these studies include Knack and Keefer (1995), Beck et al. (2000), Beck and Levine (2003), Beck et al. (2003), Acemoglu et al. (2001)and Acemoglu et al. (2002). Besley (1995) has found a strong linkage between investment and property rights. The literature has, further, demonstrated the importance of political liberalization for financial development (Olson (1993)). Recent papers have also explored the impact of property rights and other legal institutions on international stock market returns for both developed and emerging economies. Legal 
origins have been proved to have a significant impact on shareholders' rights and creditors' rights and contract enforcement.

This paper focuses on the importance of political institutions for financial asset market returns of various economies. Overall, democracy has a positive impact on growth by providing checks on government power and providing stringent rules of law which can protect private property. Yet economists argue that democratization of an economy has a negative impact on growth because it leads to rich-to-poor redistributions of income and provides privileges to special interest groups. Research has found a non-linear impact of democracy on growth Barro (1996). Though most developed economies have democratic institutions, the effect of democracy on the overall development of an economy is not obvious. Among other factors, democratization of an economy seems to have a positive effect on the financial growth and level of investment of an economy. Busse (2003) has proved that "on average" investment by multinationals is significantly higher in countries with democratic institutions. Political institutions have also been shown to have a positive effect on the financial development of an economy Huang (2005).

Do efficient political institutions have any impact on asset returns in an economy? This paper explores the relationship between political regime and asset returns in an extended CAPM framework. The Capital Asset Pricing Model (CAPM) is the most popular model dealing with the determination of expected returns on securities and other financial assets. Efficient institutions help to secure property rights which, in turn, are crucial for affecting the investment pattern of firms. The investment pattern of firms and the degree of protection on the return of assets seem to be strongly attached to the institutional framework of an economy.

This paper explains the importance of institutions for the financial markets of an economy. The inherent institutional characteristics of an economy can change the average return of assets. My findings suggest that political institutions play a significant role in the average stock returns of assets. Democracy has a positive impact on the average stock return of assets 
since it provides an environment with secured property rights, lower risks of expropriation by the government, less corruption and favorable investment condition. The institutional quality of an economy is found to have a negative relationship with the average stock return of assets. Autocratic institutions have compensations for greater chances of defaults of bankruptcy, political instability and nationalization of assets. As the quality of institutions improves over time, it enhances the value of the firms which, in turn, leads to initial higher realized returns and, subsequent, lower average returns on assets. Thus, even controlling for systematic risk, the inherent institutional characteristics of an economy significantly affect the stock market.

There is a previous literature on the development of stock markets in emerging economies. Funke (2002) finds a significant effect of stock market development on private consumption spending. Phylaktis and Ravazzolo (2004) studied the stock market linkages of a group of Pacific-Basin countries. Harvey (1995) has studied the process of market integration for emerging markets. Others have specifically focused on the impact of institutional quality on the investments in stock markets. Clark and Tunaru (2003) developed a model for measuring the cost of political risk in emerging countries. L'Her and Suret (1997) analyzed the hyperreturn periods for 20 emerging countries from 1976 to 1994. Perotti and VanOijen (1999) showed in their paper that progress in privatization has a crucial role in stock market development by resolving political risk. Though the literature has explored the role of political risk in the stock market development in emerging markets, little has been shown empirically regarding the specific relationship between political institutions and asset returns. This paper studies whether the political regime plays a crucial role in the asset returns for economies even after controlling for financial risks and other political risks. It adopts a CAPM framework with the two pass methodology approach. Alternative models and several regression specifications further prove the robustness of the findings. Though the original sample consists of 17 emerging countries, an unbalanced panel of 30 countries is also considered as part of the robustness analysis. 
The paper is structured as follows. Section II states the hypothesis and reviews the role of political institutions in financial markets and stock returns. Section III describes the data and its sources. Section IV describes the testing methodology and presents the main empirical results. Section V presents additional empirical results with alternative proxies of political institutions. Section VI discusses the robustness issues by stating some alternative specifications to the standard market risk model. Section VII justifies the rationale for including additional control variables and explores their impact on the asset returns. Section VIII conducts some additional robustness tests and explains the results. Section IX concludes.

\section{Hypothesis Development}

Economists have long shown that institutions play an integral role in the overall development of a nation. Recent work has documented that institutions also play a significant role in the development of financial markets for an economy.Beck and Levine (2003) argue that extractive colonizers tend to create extractive institutions which do not protect private property rights but support an elite group. On the other hand, producer-friendly institutions created by settler colonizers support private property. Thus, such institutions lead to the overall development of the financial market. Further, Rajan and Zingales (2003) argue that special interest groups have strong incentives to block the development of a transparent and competitive financial sector. Yet, these incentives may be weakened with the opening of international trade and the international flows of capital. La Porta et al $(1997,1998)$ have examined the importance of legal institutions for the financial development of a country. Protection of property rights, contract enforcement and good accounting principles are essential features for the development of financial markets of an economy. They have shown that countries of British legal origin have better financial markets than French common law

countries that have inefficient contract enforcements and more corruption. Recently, it has 
been argued that political liberalization of a country has a significant impact on its financial development. Huang (2005) finds that enhanced institutional quality is associated with improvements in financial development, particularly for low income countries with high ethnic diversity and French legal origins.

Political liberalization or expansion of political freedom is usually termed as democratization of an economy. Economists argue that democracy is both a facilitator and impediment of growth. Proponents of democracy argue that such institutional structure enhances fundamental civil liberties, maximizes economic freedom, promotes property rights protection, allows for the most efficient use of resources and discourages corruption and lawlessness. Some of the papers which talk about these issues are Olson (1993), Clague et al. (1996), Minier (1998), Persson (2005) and so on. Further, democracy boosts investment in an economy and facilitates contract enforcement which, in turn, affects investment indirectly. North and Weingast (1989) proved that political institutions characterized by checks and balances can allow governments to credibly commit and, thus, there is little danger of opportunism. Democracy also imposes sufficient checks on elite groups who tend to restrict participation in the political system and protect their own interests. Research shows that trade openness enhances the prospects of financial development through the channel of better institutional quality (?). Democracy also smoothes access to external credit by firms which leads to efficient investment decisions by the economy. The counter examples are that democratic structures may suffer from inefficiency in decision making under pressure from different interest groups. Autocrats, on the other hand, are better able to handle societal demands and can efficiently deal with labor unions, wages and consumer demands.

Betterment of political institutions is crucial for the efficient functioning of financial markets. Enforcement of laws is much more erratic where executive powers are concentrated in the hands of a privileged few such as in autocratic regimes. Both legal and political institutions curb insider trading and, thus, reduce the information risk in stock trading. Weak legal institutions tend to create narrow capital markets due to the information lag 
between insiders and outsiders (La Porta et al, 1998). This enhances the risk of investing in such environments. Political risk has also been shown to be deterrent factor for investing in stock markets Clark and Tunaru (2003). Portfolio investment is affected when people is unable to anticipate the changes in the business environment resulting from political instability. Further, wars, social upheavals, riots, strikes all form part of political risks and are capable of affecting portfolio investment of firms. All these factors have a strong correlation with the political regime of a nation. Democracies are less prone to deaths, riots, political strikes, sabotage and assassinations and, hence, considered more stable K.Gupta et al. (1997). Thus, investors are more confident in investing in economies with efficient legal protection and less prone to political risks. Autocracies are more susceptible to factors causing political instability and, thus, have a negative impact on portfolio investment by firms.

The relationship between political liberalization and stock returns is explored in a CAPM framework. The Capital Asset Pricing Model (CAPM) is the most popular model for valuing securities by relating risk and expected return. The model is used for estimating the cost of equity capital for firms and for evaluating the performance of managed portfolios. It is based on the idea that investors can earn a risk premium or additional expected return if they are willing to undertake more risk. The investors need to be compensated for two factors, the time value of money, which represents the risk free rate, and the risk. Beta is a key component in the CAPM, which represents the risk of the asset. It is a measure for the stock's volatility in relation to the market. Alder and Dumas (1983) extended the standard CAPM to the international perspective by incorporating disparities in the purchasing power parity. Nilsson (2002) adopts a conditional CAPM framework to show that there are significant benefits of international diversification of portfolios. Chang, Errunza, Hogan and Huang (2005) show that the expected international asset return is determined by a weighted average of market risk, market hedging risk, exchange rate risk and exchange rate hedging risk.

There are two aspects of risk related with investment in assets. Theoretically, investors 
are not compensated for one-sided or unsystematic risk. Investors are compensated for the market risk or two-sided risk. Under normal circumstances, people require a mark up on returns on assets due to risks of bankruptcy, nationalization and political instability. Over a short sample period, these risks may not fully materialize and hence we observe that average return exceed the required returns. For autocratic institutions, the average return on assets is higher than required returns. For such institutions, the probabilities of nationalization, political instability, and defaults are much higher and the investors need to be compensated for such risks. In particular, due to our small sample period, the true nationalization risk is not observed. If nationalization of assets is observed over an infinite sample period, CAPM would imply that the average return is equal to required return. Thus, in actual sample periods different economies may have different average returns even though the systematic risk is same for all of them. Conditional on the occurrence of asset nationalization, the inherent political characteristics of an economy have significant impact on average asset returns of emerging economies. Thus, the fact that the average returns are higher than the required returns in autocratic countries can partly be explained by the fact that the expected nationalization of the assets, for which investors require insurance premium, has not yet occurred in my sample.

\section{Data}

The paper uses industry-specific and country-specific data from a variety of sources. The sample consists of 17 developing countries. The major source of the data is the Emerging Market Database (EMDB) 2000 from International Finance Corporation (IFC).This dataset provides data on the closing price indices of the various stocks and also the local currency indices of the stocks of various countries. These price indices are converted to obtain the stock return and the local market return. The local market returns are multiplied by the appropriate exchange rates to obtain the returns in US dollars. The World indices are from 
the Morgan Stanley International Database. The MSCI World Index is a free float-adjusted market capitalization index that is designed to measure global developed market equity performance. The index consists of 23 developed market indices. The Fama French site provides the data for the US risk free rate. Monthly data are used for all the indices.

The additional variable of interest in the paper is the 'Polity' variable. The source of this variable is the Polity IV project which codes the authority characteristics of the states in the world system for purposes of comparative and quantitative analysis. To facilitate empirical analysis of the process of political democratization and historical trends, Polity IV constructed annual measures for both institutionalized democracy (DEMOC) and autocracy (AUTOC) as mixed trends of both of these distinct authorities are blatant in several economies. A third indicator 'Polity' is derived by subtracting the AUTOC score from the DEMOC score which provides a single regime score ranging from -10 to +10 . Both the autocracy and democracy score are based on the competitiveness of political participation, the openness and competitiveness of executive recruitment and constraints on the chief executive. Finally, periods of interruption, interregnum and transition are assigned scores of $-66,-77$ and -88 respectively. In order to facilitate the use of the 'polity' regime measure, this paper uses the modified polity variable termed Polity 2 which assigns standardized values to the periods of interruption, interregnum and transition periods. It also ranges from a scale of -10 to +10 . The sample period considered for the balanced panel ranges from 1987 to 2000. Polity2 is referred to as 'polity' throughout the paper.

There is a different set of variables which also focuses on the risk aspects of an economy. These are the International Country Risk Guide (ICRG) variables which categorize political, economic and financial risks. Each risk consists of several components that are assigned a maximum numerical value. The ICRG variables assess the political stability of an economy in terms of the various risk elements. A score of 0 denotes a high risk situation for each of the variables while a higher score denotes the minimum risk situation. One of the variables of the ICRG database is the 'democratic accountability' variable which is a measure of 
how responsive is the government to the needs of the people. The variable weighs the accountability of the government as a risk factor. This paper particularly explores the impact of institutional characteristics on asset markets. The polity variable seeks to measure the institutional quality of an economy based on the freedom of suffrage, the efficiency of civil and political liberties and the operational constraints on the executive. Since the ICRG variables focus on the risk factors and not the inherent political aspects of an economy, the study maintains polity as the main variable of interest. The ICRG variables are only used as control variables and for robustness tests.

Due to unavailability of data, the set of countries is reduced to a sample of 17 countries. The complete dataset of EMDB provides data from 1986 to 2000 for a sample of 30 emerging countries. To avoid an unbalanced panel, I have run the results over the reduced sample set. This sample is balanced across countries, though the sample is still unbalanced on a firm level. The results are rerun with an unbalanced sample of all the 30 emerging economies for robustness. Table (1) presents list of variables used in the paper. Table (2) presents the summary statistics of the variables. Table(3) presents the correlation matrix of the ICRG variables and initial and mean polity variables.

\section{The Regression Framework}

The standard methodology of estimating the CAPM or any of its extensions is the two-pass regression method. It is the most popular methodology in empirical asset pricing literature developed by Black et al. (1972) and Fama and McBeth (1973). It is used for estimation of risk premia and testing beta asset pricing models. Although there are many variations of the two-pass methodology, the basic set up always involves two steps. The properties of the test statistics and goodness-of-fit measures under the two-pass methodology are usually developed under the assumption that the asset pricing model is correctly specified and that the factors are correctly identified. In the first pass, time series estimates of the individual 
asset betas are obtained by ordinary least squares (OLS). The firm-level assets are sorted into the respective country portfolios. This is done to reduce the chances of measurement errors in the betas generated in the first pass. The dependent variable in the first pass is the excess return of stocks over the risk free rate for each country. The specification for the regression in the first pass is as follows

$$
r_{i j}-r_{f}=\alpha_{i j}+\beta_{i j}^{W}\left(r_{w}-r_{f}\right)+\eta_{i j}, \quad i=a, b,
$$

where firm a in country $j$ is indicated by index $i$. In this case, the first pass is run for every country individually. I create equally-weighted portfolios based on the firms in each country. Since the systematic risk of each country is the most important component in explaining security returns, equally weighted country portfolios are constructed which reduces the idiosyncratic risk component of each emerging country firm. The risk is minimized due to the diversification benefits among the assets of different countries. The term on the right is the excess world market return which is the same for each country since the returns are all in one common currency. The second pass regression is conducted on the average returns of assets by using the estimated betas from the first pass as independent regressors. Following Fama and French (1992), the country betas obtained from the first pass are applied to individual assets while running the second-pass regressions. The second-pass regression equation is as follows,

$$
\overline{r_{i j}}-\overline{r_{f}}=a+b \beta_{i j}^{W}+c M e a n X_{i}+d \operatorname{Initial} X_{i}+\varepsilon_{i}, \quad i=a, b,
$$

where $\beta_{i j}^{W}$ denotes the beta of the world excess return and $\mathrm{X}$ denotes a proxy for the political regime. The key variable of interest is InitialX $_{i}$. Further, Mean $X_{i}$ controls for the differences in the average polity regime scores of economies. Changes in institutional quality over time can lead to significant capital gains or losses and 'mean polity' controls for this particular effect. Table (4) presents the second pass regression results. Column (1) 
presents the benchmark results. The results reveal that polity plays a significant role in asset returns of economies. Initial polity variable is significant in explaining stock returns at the 1 perecnt level. The initial polity has a negative relationship with the average return since a lower polity score implies a more autocratic regime, more political, economic and financial risks and, thus, average returns are higher than required returns. The investors need to be compensated for the higher chances of nationalization. The initial polity proxies for the compensation of nationalizations, implying that more autocratic institutions should have higher average return. The results reveal that a point increase in initial polity lowers average return by 10 basis points. It seems that idiosyncratic risk is priced. This can only happen, according to the CAPM, if the economies are not fully integrated or there is unobserved one-sided risk. The figures also suggest that a one standard deviation (S.D.) increase in initial polity reduces average asset return by 7 percentage points annually. Mean polity has a positive impact on the average return of assets but is not significant. Starting from the initial level, as institutions become more democratic it generates higher cash flows and the value of the firm increases to the investors. This generates higher realized returns and, subsequent, lower average returns of assets. The robustness of the result is tested by using median polity instead of mean polity (figures not reported). Initial polity remains negative and significant. The $\mathrm{R}$ square and the adjusted $\mathrm{R}$ square are almost identical for both the regressions. For both mean and median polity, risk premium on beta is negative but highly insignificant. The intercept is positive but small.

\section{$5 \quad$ Using other Proxies for Political Institutions}

To test the robustness of the findings, some other proxies for political institutions might be worth considering. The database of the political institutions (DPI) is used for checking the robustness of the results. The database includes several variables characterizing the political structures of an economy. The only variable relevant for our hypothesis is the TENSYS 
variable which states the time length a country has been autocratic or democratic. Higher scores denote more democratic institutions. The second pass regression with the alterative political proxy is stated as follows

$$
\overline{r_{i j}}-\overline{r_{f}}=a+b \beta_{i j}^{W}+c M e a n Z_{i}+d \text { Initial } Z_{i}+\zeta_{i}, \quad i=a, b,
$$

where $Z_{i}$ is the TENSYS variable. The results are reported in Column (2) of Table (4). The conclusions are robust with the alternative proxy of political institutions. Initial TENSYS is negative and significant at the 1 perecnt level which suggests that higher probabilities of defaults demand higher return as compensation based on the assumption that nationalization has not occurred. Mean TENSYS variable is positive and significant at the 1 perecnt level implying that an improvement in the political environment generates positive cash flows. According to the figures, a one S.D. increase in initial TENSYS reduces average return of assets by 12 percentage points annually. The $R^{2}(0.012)$ falls with the alternative proxy in relation to polity. The regressions are also run with median TENSYS and the results are robust.

\section{An Alternative to the Market Risk Factor}

An alternative model to the standard CAPM risk model, which can be used to test the robustness of the results, is the Fama French three factor model. Fama and French (1993) find 'value' and 'size' to be the most significant factors together with market risk, for explaining the realized return of assets. The size factor is termed SMB which stands for Small Minus Big. It is designed to measure the additional returns generated by investing in stocks of companies with relatively small market capitalization. The HML factor, which stands for the High Minus Low, measures the additional return generated to investors for investing in companies with high book-to-market ratio. SMB and HML are shown to have the greatest

predictive powers of any additional factors. The regressions are run by including the value 
and size factors in the first pass along with the market risk factor. The Fama French site provides the data for the 'US SMB' and 'US HML'.

Alder and Dumas (1983) first introduced the International CAPM (ICAPM) which takes into account the possible deviations from purchasing power parity. The theory suggests that since investors are risk averse and foreign exchange risk is not fully diversifiable, an exchange rate risk component is needed to explain excess returns. Thus, from a foreign consumer's perspective, utility varies both due to variations in wealth and due to variations in the purchasing power of wealth. Yet, the addition of exchange risk has proved inconclusive in the earlier literatures. (Giovannini and Jorion, 1989; Jorion, 1991; Korajczyck and Viallet, 1990). Dumas and Solnik(1995) and De Santis and Gerard(1998) show that a time varying exchange rate risk is statistically significant in a conditional CAPM framework. The first pass regression after incorporating SMB, HML and exchange factors appears as follows:

$$
r_{i j}-r_{f}=\alpha_{i j}+\beta_{i j}\left(r_{w}-r_{f}\right)+s_{i} S M B_{i}+h_{i} H M L_{i}+\delta_{i j}+\theta_{i j}, \quad i=a, b,
$$

where $\mathrm{n}$ denotes the number of countries in the sample. The second pass regression results prove the robustness of the findings . Table (5)presents the results. The coefficient of initial polity variable is negative and significant. Mean polity is positive but insignificant. Both the world risk premia factor and the market capitalization factor are insignificant while the value factor turns out to be significant. Other than the exchange risk factor of British currency, the other two exchange risk returns are positive. The robustness of the findings is also tested by using median polity instead of mean polity. The $\mathrm{R}$ square remains similar with the alternative set of values of polity.

\section{Robustness}

The International Country Risk Guide (ICRG) variables represent the set of institutions which are suggestive of the political, economic and financial risks affecting the economy. 
Democratic institutions lower chances of corruption, raise political stability enhance economic freedom, and ensure respect for property rights (Persson (2005), Tavares and Wacziarg (2001)). Thus, it seems reasonable to check separately the impacts of corruption, conflicts, and law and order on the stock market development of economies. Specifically, these variables are used since they are most relevant to our analysis. I include the variables of corruption, internal conflict, external conflict and law and order from the ICRG dataset. The results are presented in Table (6). All results indicate similar conclusions that an enhancement of default chances in the economy increases compensation on assets since people perceive a mark up over the average rate of return under such circumstances. The initial corruption variable has a negative impact on the average stock return of assets conditional on the fact that nationalization of assets has not taken place. The higher the score, the lower is the corruption level of the economy and the lower is the average stock return of assets. Investing in a less corrupted atmosphere implies fewer chances of defaults and, thus, average stock returns are lower. The mean corruption level has a positive impact on the return of assets signifying that an improvement in the corruption situation generates positive returns. Similarly, the initial levels of the other variables like external conflict, internal conflict, and law and order also have a negative impact on the average asset returns supporting the findings that the stock returns are higher for economies with greater political risks.

The ICRG variables control for the aspects of political instability of the economy not captured by the polity variables. I have used the ICRG variables as additional controls in the second pass regression. Yet, adding the ICRG variable provides multicollinearity issues as it involves high correlation of the variables with the polity data (See Table(3)). The regressions are rerun by considering the residuals of the ICRG variables. Initial ICRG and mean ICRG variables are regressed on both initial and mean polity variables and then the residuals are used as control variables in the second pass. The significance of initial polity is not lost with the inclusion of the residuals for all the regressions. For the specification with corruption, a one S.D. increase in initial polity reduces average return by 1 percentage 
points monthly. The initial corruption variable has a negative and significant impact on the average return of assets. Further, the mean of the corruption variable has a positive impact on returns. Both initial and mean corruption variables are significant at the 1 percent level. For the external conflict variable, the initial score has a negative and significant impact on the stock return of assets but the mean is insignificant. It may be that the corruption variable affects the returns more strongly than the external conflict variable. For most of these specifications initial polity remains significant throughout while mean polity remains insignificant. The residual of initial ICRG variables are mostly significant but mean is not significant for most of the regressions. The world risk premium becomes positive for most of the specifications. Since polity may not be a perfect proxy for political institutions, the results are also checked with the TENSYS measure. The second pass regression is rerun by adding the ICRG residuals as additional controls. The significance of initial polity remains unaltered with the alternative measure. Additionally, the mean polity is significant for all the specifications. The world risk premium is still insignificant but is positive for most of the specifications. Though the residuals of initial values of the ICRG variables remain significant for most of the specifications, the mean loses its significance. Further, the results are checked by considering the alternative model to the standard CAPM model. The first pass is run with six factors consisting of the world risk premia, the Fama French factors and the exchange rate risks. The residuals of the ICRG variables are added in the second pass along with the political proxies. The results prove the robustness of the findings. Initial polity is negative and significant for all the specifications.

\section{Further Testing for Robustness of the Results}

The results are, further, tested by including additional controls. These variables control for the financial structure of an economy. Two measures for financial development are used as control variables. The measures are 'stock market capitalization divided by GDP' and 
'stock market total value traded over GDP'. Since the focus of the paper is the development of the stock markets, these two measures are considered. The data is taken from the Beck et al. (2003) database. Both initial and the mean values of the financial development variable are used as additional controls in the second pass regression. The second pass regression equation is as follows

$$
\overline{r_{i j}}-\overline{r_{f}}=\gamma_{1}+\gamma_{2} \beta_{i j}^{W}+\gamma_{3} \text { MeanX } X_{i}+\gamma_{4} \text { Initial }_{i}+\gamma_{5} \text { MeanF }_{i}+\gamma_{6} \text { InitialF }_{i}+v_{i}
$$

where F implies a measure for financial development. Column (3) of Table (4) presents the results with the stock market capitalization measure while Table presents the results with the alternative measure. Initial polity is negative and significant for both measures proving the robustness of the findings. A one S.D. increase in initial polity lowers average asset return by 6 percentage points annually for total value of stocks traded over GDP measure. The mean becomes negative for the stock market capitalization measure but it is positive for the alternate one. Initial financial development variable has a strong impact on the average asset return for both measures. The mean has a significant and positive impact on the asset return for the stock market capitalization measure. The results signify that even after controlling for the financial development of an economy, political institutions play a significant role on the development of stock markets. The world risk premia becomes relatively significant with the inclusion of financial development variables. The robustness of the results is checked by running the regressions with the ICRG residuals. Initial polity remains negative and significant for almost all the regressions. Mean and initial financial development variables remain mostly significant for the two alternative measures. The world risk premium is positive and significant for the specifications.

Mean polity controls for the changes in institutional quality over time. For an infinite sample, the capital gains or loses, due to changes in institutional quality, asymptotically approaches zero. Since I have a finite sample, I control for mean polity in the second pass 
regressions. For robustness, the specification is rerun without mean polity in the second pass - Initial polity remains negative and significant. World risk premia is negative and highly insignificant while the intercept is small and positive.

The unavailability of the data restricted the sample to 17 emerging countries over the sample period 1987-2000. To increase the sample size, an unbalanced panel has been considered. Inclusion of more data in the sample set reduces the measurement error. The new sample considers a set of 30 emerging countries over the sample period 1986 to 2000. The results are robust to the findings. With the larger dataset, both initial and mean polity is significant at the 1 perecnt level. Initial polity has a negative impact on asset return while mean polity has a positive impact. This suggests that autocratic institutions are susceptible to greater probabilities of nationalization which need to be compensated. The results are robust with median polity.

\section{Controlling for Economic Freedom}

Studies and, in fact, past experiences have shown that economic freedom of a country is more important for the growth and development prospects on an economy rather than the inherent democratic institutions of the nation. The most prominent example in this respect are nations like Hong Kong and Japan which have autocratic institutions but are ranked very high on the economic freedom ranking. These nations have advanced at an astonishing pace in the past few decades and have per capita income comparable to nations like United States, United Kingdom and Canada.

The term economic freedom implies the encouragement of market economy where voluntary exchange can take place smoothly, greater competition is supported and there is high respect for property rights. Economic freedom has been defined as "the absence of government coercion or constraint on the production, distribution or consumption of goods and services beyond the extent necessary for citizens to protect and maintain liberty themselves." 
The components involves factors like the amount of tax regulations on trade, the extent of government expenditures, the structure of legal system and property rights of a nation, the extent of regulations on credit and labor market and the stability of the monetary system. Thus, it is reasonable to assume that the investment decisions should be definitely determined to a great extent by the amount of economic freedom of a nation. Thus, research has recognized the importance of economic freedom in generating growth and prosperity of a nation.

Some literature has also established the importance of economic freedom in the context of foreign direct investment inflows to a nation. Foreign investors look for transparency in economic policies and also lesser constraints in business environment. The same argument is true for domestic investors. Lack of the factors mentioned above will lead lack of information in the market and also about the intention of the government. Thus, they will be skeptical about investing in such situations.

Thus, the results are checked by including economic freedom and its different components in the second pass - both initial values and the means of the variables. The main hypothesis is that countries with lower economic freedom have higher probabilities of nationalization, political stability and default and, thus the investors need to be compensated for such risks. I include the proxy for economic freedom and the different components as independent regressors and also as controls along with polity. I run several regressions to establish the robustness of my findings. The data is taken from Fraser Institute. Other than the main variable - economic freedom, the other components considered are the size of the government, the structure of legal and property rights, access to sound money, taxes on international trade and restrictions on the credit market. The initial set of regressions are run by including both initial and mean economic freedom along with initial and mean polity. Initial polity remains negative and significant and mean polity becomes even more significant. But economic freedom is insignificant. The results remain the same for all the components of economic freedom except credit market restrictions. The initial value for credit market restrictions 
has a negative impact on average return of assets. The results are rerun by considering only the initial value of economic freedom and with any polity variables. In this case, economic freedom and all its components are negative and significant. The results are robust when the regressions are rerun with initial polity and initial economic freedom. Both initial polity and initial economic freedom are negative and significant for the economic freedom variable and all the other components.

\section{Conclusion}

The indispensable role of political institutions in the overall development of an economy is well established in the literature. Political institutions also have a crucial impact on the financial infrastructure of an economy. This paper stresses the role of political institutions in the development of stock markets in emerging markets. Enhancement of political institutions implies more political stability due to the inherent link between them. Such economies create investor friendly environments for the investors who can invest under low-risk conditions. Democratic institutions provide an environment with secured property rights, lower risks of expropriation by the government, well developed capital markets and favorable investment condition. The results suggest that better political institutions have a negative relationship with asset return conditional on the fact that the nationalization of assets has not occurred. Firms in autocratic regimes have higher average returns that exceed the required returns which is consistent with the fact that autocratic institutions are more prone to political and financial risks. In CAPM framework over long enough period of time average returns should be equal to the required returns. The fact that the average returns are higher than the required returns in autocratic countries can partly be explained by the fact that the nationalization of the assets, for which investors require insurance premium, has not yet occurred in my sample.

The results are robust to various sensitivity analysis. The results are checked with an 
alternative proxy for political institutions. Several control variables are included to account for political and financial risks of the economy. Specific variables from the ICRG dataset, which are relevant to the analysis, are considered to control for political risk. Alternative financial development measures are used as rationales for financial risks of economies. The conclusions are robust with all these alternative specifications. Additionally, the hypothesis is tested with the alternative Fama French three factor model and the results are robust. The results are also robust with an unbalanced panel of 30 emerging economies. This strongly justifies the hypothesis that betterment of the political institutions is critical to the development of stock markets for emerging economies. 


\section{Table 2.1: Variables and Sources}

\begin{tabular}{|l|c|}
\hline Variable & Sources \\
\hline Closing Price Indices & EMDB (2000) database \\
Local Price Indices & EMDB (2000) database \\
World Index & MSCI International Database \\
Risk Free Rate & Fama French Database \\
SMB, HML & Fama French Database \\
TENSYS & Beck et. al. (2000) \\
Stock Market Capitalization Over GDP & Beck et. al. (2000) \\
Stock Market Total Value Traded Over GDP & \\
\hline
\end{tabular}


Table 2.2: Overall Summary Statistics

\begin{tabular}{|l|ccccc|}
\hline & Observations & Mean & S.D. & Maximum & Minimum \\
\hline Exchange Rate & 2856 & 7188.97 & 53573.16 & 682840 & 0.000133 \\
\hline POlity & 2856 & 4.6428 & 5.2998 & 10 & -9 \\
\hline TENSYS & 2856 & 18.26 & 15.89 & 61 & 0 \\
\hline Stock Market Capitalization & 2856 & 0.3890 & 0.4394 & 2.824 & 0.014 \\
\hline Stocks Traded & 2856 & 0.334 & 0.768 & 6.323 & 0.0001 \\
\hline Corruption & 2856 & 3.254 & 0.862 & 5 & 1.083 \\
\hline External Conflict & 2856 & 9.765 & 1.995 & 12 & 4 \\
\hline Internal Conflict & 2856 & 8.578 & 2.577 & 12 & 2.167 \\
\hline Law and Order & 2856 & 3.610 & 1.309 & 6 & 1 \\
\hline
\end{tabular}

Table 2.3: Correlation Matrix of the Polity and the ICRG Variables

\begin{tabular}{lcccccc}
\hline & Mean Pol & Initial Pol & Conflict(Int) & Conflict(Ext) & Corruption & Law \\
\hline Mean Polity & 1 & 0.8044 & 0.1244 & 0.1932 & 0.2726 & 0.3020 \\
Initial Polity & & 1 & 0.1514 & 0.2080 & 0.2087 & 0.2165 \\
Internal Conflict & & & 1 & 0.6201 & 0.4968 & 0.7964 \\
External Conflict & & & & 1 & 0.4160 & 0.4430 \\
Corruption & & & & & 1 & 0.4558 \\
Law and Order & & & & & & \\
\hline
\end{tabular}




\section{Table 2.4: Second Pass Regressions With Polity, TENSYS and Controlling for Financial Development}

\begin{tabular}{lccc}
\hline Independent Variables & 1 & 2 & 3 \\
\hline \multirow{2}{*}{ Intercept } & & & \\
& $-7.23 \mathrm{e}-08^{* * *}$ & -0.001 & $0.007^{* * *}$ \\
World Beta & $(1.08 \mathrm{e}-08)$ & $(0.293)$ & $(0.363)$ \\
& $0.000963^{* *}$ & -0.001 & $0.007^{* * *}$ \\
Institution & $(0.000397)$ & $(0.293)$ & $(0.363)$ \\
& $0.258^{* * *}$ & -0.001 & $0.007^{* * *}$ \\
Initial Institution & $(0.0678)$ & $(0.293)$ & $(0.363)$ \\
& $60.69^{* * *}$ & -0.001 & $0.007^{* * *}$ \\
Institution & $(3.619)$ & $(0.293)$ & $(0.363)$ \\
& $0.258^{* * *}$ & -0.001 & $0.007^{* * *}$ \\
Initial Institution & $(0.0678)$ & & \\
& $60.69^{* * *}$ & -0.001 & $0.007^{* * *}$ \\
& $(3.619)$ & & \\
$R^{2}$ & & & \\
\hline \multicolumn{4}{c}{ Standard errors in parentheses } \\
$* * *$ & 0.093 & &
\end{tabular}

The first pass regressions are not reported. The World Beta is the estimated beta from the first pass. In the first pass, the excess stock return of firms is regressed on the world excess return and the estimated betas are generated. The independent regressors of the second pass are the estimated betas from the first pass and additional variables, initial and mean polity. Initial polity variable is the proxy for political institutions which is included in the second pass while mean polity is used as a control for changes in institutional quality. 
Table 2.5: Second Pass Regressions with Polity, Fama French Factors and Exchange Rate Factors

\begin{tabular}{|c|c|}
\hline Independent Variables & Estimates \\
\hline Intercept & $\begin{array}{l}0.006 \\
(1.105)\end{array}$ \\
\hline World Beta & $\begin{array}{l}-0.005 \\
(-0.882)\end{array}$ \\
\hline Beta for Size & $\begin{array}{l}-0.002 \\
(-0.259)\end{array}$ \\
\hline Beta for Value & $\begin{array}{c}-0.012^{* *} \\
(6.040)\end{array}$ \\
\hline Beta for German Marc & $\begin{array}{c}0.002^{* *} \\
(0.698)\end{array}$ \\
\hline Beta for Japanese Yen & $\begin{array}{c}0.003^{*} \\
(1.247)\end{array}$ \\
\hline Beta for British Pound & $\begin{array}{c}-0.007^{*} \\
(-1.832)\end{array}$ \\
\hline Institution & $\begin{array}{c}0.00038 \\
(1.111)\end{array}$ \\
\hline Initial Institution & $\begin{array}{c}-0.00101^{* * *} \\
(-4.397)\end{array}$ \\
\hline$R^{2}$ & 0.03 \\
\hline
\end{tabular}

The first pass regressions are not reported. In addition to the world risk premia, the first pass has the market capitalization factor, the value factor and exchange rate risk factors as the independent variables. The independent regressors of the second pass are the estimated betas from the first pass and additional variables, initial and mean polity. Initial polity variable is the proxy for political institutions which is included in the second pass while mean polity is used as a control for changes in institutional quality. 


\section{Table 2.6: Second Pass Regressions with ICRG variables}

\begin{tabular}{|c|c|c|c|c|}
\hline Independent Variables & Estimates & Estimates & Estimates & Estimates \\
\hline Intercept & $\begin{array}{c}0.001 \\
(0.0486)\end{array}$ & $\begin{array}{l}0.0193 \\
(1.267)\end{array}$ & $\begin{array}{c}0.017^{* * *} \\
(4.551)\end{array}$ & $\begin{array}{c}0.013^{* * *} \\
(4.237)\end{array}$ \\
\hline World Beta & $\begin{array}{l}0.0001 \\
(0.043)\end{array}$ & $\begin{array}{c}0.002 \\
(0.480)\end{array}$ & $\begin{array}{c}0.003 \\
(0.842)\end{array}$ & $\begin{array}{c}0.002 \\
(0.567)\end{array}$ \\
\hline Mean Corruption & $\begin{array}{c}0.00954^{* * *} \\
(2.861)\end{array}$ & & & \\
\hline Initial Corruption & $\begin{array}{c}-0.00873^{* * *} \\
((3.402))\end{array}$ & & & \\
\hline Mean External Conflict & & $\begin{array}{c}0.00115 \\
(0.615)\end{array}$ & & \\
\hline Initial External Conflict & & $\begin{array}{c}-0.00301^{* * *} \\
(-5.333)\end{array}$ & & \\
\hline Mean Internal Conflict & & & $\begin{array}{c}-0.00023 \\
(-0.354)\end{array}$ & \\
\hline Initial Internal Conflict & & & $\begin{array}{c}-0.00166^{* *} \\
(-2.326)\end{array}$ & \\
\hline Mean Law and Order & & & & $\begin{array}{l}-0.00046 \\
(-0.353)\end{array}$ \\
\hline Initial Law and Order & & & & $\begin{array}{c}-0.00275^{* *} \\
(-2.310)\end{array}$ \\
\hline
\end{tabular}

Standard errors in parentheses

${ }^{* * *} \mathrm{p}<0.01,{ }^{* *} \mathrm{p}<0.05,{ }^{*} \mathrm{p}<0.1$

The first pass regressions are not reported. In addition to the world risk premia, the first pass has the market capitalization factor, the value factor and exchange rate risk factors as the independent variables. The independent regressors of the second pass are the estimated betas from the first pass and additional variables, initial and mean polity. Initial polity variable is the proxy for political institutions which is included in the second pass while mean polity is used as a control for changes in institutional quality. 


\section{Chapter 3}

\section{The Amplification Effect: Foreign}

\section{Aid's Impact on Political Institutions}

\section{Introduction}

There are two competing hypotheses about how foreign aid affects recipient-countries' political institutions. The first hypothesis is optimistic about aid's impact on political regimes. According to this view, foreign aid can have a positive effect on developing countries' political institutions by making them more democratic. The second hypothesis is pessimistic. According to this view, aid is not only unable to promote democracy in recipient nations, but often has the opposite effect, leading to weaker democracy or more dictatorship in recipient countries.

This paper offers a third hypothesis about aid's impact on recipient-country political institutions. We call this hypothesis the amplification effect. According to our hypothesis foreign aid neither causes democracies to become more dictatorial nor causes dictatorships to become more democratic. It only amplifies recipients' existing political institutional orientations. In countries with relatively centralized political institutions-" dictatorships"-foreign aid causes political institutions to become more centralized. Aid makes dictatorships more 
dictatorial. In countries with relatively decentralized political institutions-" democracies"foreign aid causes political institutions to become less centralized. Aid makes democracies more democratic.

We investigate this hypothesis using panel data for 73 developing countries between 1975 and 2003. Our results support the amplification hypothesis. The optimistic view of foreign aid's ability to improve democracy in recipient countries is overly optimistic. If aid is given to a developing country with centralized political institutions in the hopes that it will become less centralized, just the opposite can be expected to happen. Rather than becoming more democratic, aid makes this country more dictatorial than it began. However, the wholly pessimistic view that argues that foreign aid tends to weaken democracy or promote dictatorship in recipient nations is equally mistaken. A democratic nation that receives foreign aid becomes more democratic, rather than less democratic in its institutional makeup, than if it received no aid at all. In short, foreign aid amplifies recipients' existing political institutions rather than fundamentally changing them.

Our results partially parallel the findings of Burnside and Dollar (2000) and Svensson (1999) who find evidence for a related effect in the context of foreign aid and economic policies. This important work demonstrates that aid has a growth-enhancing effect in countries that follow economically-sound policies, but no positive effect in countries that follow economically-unsound policies. Thus, aid's ability to help or hurt a developing country depends largely on whether or not a country's government is already engaging in pro-growth activities or not. Analogously, we find that aid's ability to promote democratic political institutions depends largely on whether or not a country's government is already democratic in the first place. Our result does not perfectly parallel Burnside and Dollar's, however. While they find that aid has no effect on economic growth in the presence of 'bad' policies, we find that aid negatively affects recipient-country institutions (i.e., promotes dictatorship) in the presence of 'bad' (dictatorial) political regimes.

This finding suggests a possible channel that helps to explain Burnside and Dollar's 
(2000) claim that aid promotes growth in countries that pursue good policies, but fails to do so in countries that do not. To the extent that because of their stronger constraints on executive power democracies tend to pursue better economic policies than dictatorships, when democracies receive foreign aid they become more democratic, leading to the adoption of better policies, which in turn leads to higher economic growth. Conversely, when dictatorships receive aid they become more dictatorial, preventing the adoption of better policies, which in turn prevents increases in economic growth.

Our analysis' primary result is intuitively appealing. Foreign aid is neither a magic elixir that enhances democracy in dictatorial regimes, nor is it a potent poison that can promote dictatorship in democracies. Both the overly-optimistic and -pessimistic views about its effect on political institutions discussed above ascribe too much power to aid's ability to alter the institutional trajectory of nations. It is much more reasonable to believe that a democratic political regime will tend to use foreign aid resources in ways that enhance the democratic structure of political institutions and that dictatorial regimes will use aid resources to enhance their ability to exert authoritarian country over these institutions. After all, the existing orientation of countries' political institutions tells us a great deal about the course of institutional arrangements they pursued in the past and thus are likely to continue in the future.

Our results therefore point to a much more modest power on the part of foreign aid to affect political institutions. This does not mean that aid cannot have a sizeable impact on a country's political institutions; it certainly can. But it does mean that aid's impact is limited to one that amplifies existing institutional structures, further moving countries down the institutional paths they are already one, rather than fundamentally reversing countries' institutional paths.

The remainder of this paper is organized as follows. Section 2 discusses the potential impact of foreign aid on recipient nations' political institutions. We consider the contradictory predictions of aid's impact on recipient countries' political decentralization associated 
with the competing hypotheses discussed above and develop a third argument about how aid may affect recipient democracy/dictatorship we call the "amplification effect." Section 3 describes our data and empirical strategy for addressing these competing hypotheses. Section 4 presents our results. We look at the impact of foreign aid on both levels of and changes in political centralization in recipient countries. Section 5 examines the robustness of these results. Section 6 concludes.

\section{The Amplification Effect}

According to one hypothesis, foreign aid has significant power to transform recipient countries' political institutions for the better. By correctly supplying aid to developing countries with more centralized political institutions-autocratic or dictatorial regimes-these countries' political institutions can be become more decentralized, or democratic.

Knack (2004) points to several plausible channels through which foreign aid may be able to make more politically-centralized aid recipients more democratic. The first of these is through providing technical assistance and other support to developing countries that strengthens their judiciary and legislatures. If targeted aid can strengthen opposing branches of government in politically-centralized developing countries, it can check the power of the executive, diminishing autocratic control in the recipient countries.Second, by improving education and income, foreign aid may enhance democracy in recipient nations. Important research by Lipset (1959), Glaeser et al. (2004), and Glaeser et al. (2007), for example, suggests that becoming richer and better-educated makes countries more democratic. If this is true, and aid has the power to increase education and income among recipients, aid may also be able to promote democracy in currently dictatorial regimes.

Finally, foreign aid may promote democracy in politically-centralized recipient countries through conditionality. Aid conditionality can require increased democratization as a condition of continued assistance, compelling aid recipients to decentralize their political 
institutions. The actions of at least some members of the donor community suggest that many donors believe that aid can be an important element of democratization in politically centralized developing countries. The United States Agency for International Development (USAID), for instance, devotes more than dollar 700 million each year to programs aimed at enhancing democracy in recipient countries Knack (2004).

A second hypothesis about aid's effect on political institutions, however, is more pessimistic. According to this view, foreign aid may not only be powerless to promote democracy in dictatorial developing countries, but may actually have perverse effects on recipient countries' political institutions that make them more dictatorial as a result. Aid may therefore be a dangerous means of improving recipients' political institutions, as it has a corrosive effect on these institutions that can turn even more democratic political regimes into less democratic or more dictatorial ones.

Bauer (2000) was among the first to advance the theory that aid may make recipient countries more dictatorial instead of more democratic. According to Bauer, foreign aid suffers from an important asymmetry. In most cases, foreign aid is only a small percentage of recipients' national incomes. Thus, it has a limited capacity to improve poverty in developing nations. However, aid tends to be a large percentage of developing countries' discretionary government spending. This gives aid substantial power to increase corrupt rulers' control over resources, allowing them to further concentrate political power, which in turn leads to greater political centralization. This pessimistic view of foreign aid's effect on recipient political institutions offers precisely the opposite prediction of the optimistic about aid's impact on democracy/dictatorship discussed above.

Important work by Djankov et al. (2008) lends some support to Bauer's hypothesis. It finds that in countries that receive more foreign aid, the quality of democratic institutions weakens. According to these authors there is a "foreign aid curse" in aid-receiving countries analogous to the "natural resource curse" that plagues many resource-rich countries. Foreign aid creates resource windfalls like natural resources. Aid windfalls generate a flurry 
of rent-seeking activity that leads to greater political centralization in developing countries, much like the increased political centralization documented in the literature that examines the natural resource curse (see, for instance, Svensson (2000), Leite and Weidmann (1999). Work by Knack (2001), Knack (2004) and Brutigam and Knack (2004), which considers aid's effect on democracy and the quality of governance in Africa, supports this view. Most recently, insightful research by Rajan and Subramanian (2007) also suggests that aid reduces the quality of governance in recipient countries. Rajan and Subramanian (2005) find that aid negatively affects recipients by driving up their real exchange rates, harming their competitiveness.

The polar predictions of both the optimistic and pessimistic hypotheses about aid's effect on recipient political institutions are unsatisfactory. Both seem to ascribe too much power to foreign aid in terms of its ability to alter the institutional trajectory of recipients. On the one hand, it seem naive and overly optimistic to think that supplying more, even welltargeted, aid to brutal dictatorships, such as those in some parts of sub-Saharan Africa, will enhance democracy in these countries. The highly-centralized political regimes in these countries tend to be highly corrupt. Aid resources intended for democratization or other purposes tend to be appropriated by corrupt political officials rather than making their way to their intended ends. Further, as the pessimistic hypothesis about aid's effect on recipient political institutions suggests, aid inflows, by increasing the resources at the government's disposal, increase the payoff of being atop the political pyramid. This increased payoff creates incentives for those in political power to centralize and solidify their positions of power and encourages those at lower levels of the political ladder to try to centralize political control in their own hands. In both cases, greater political centralization, not decentralization should be expected.

On the other hand, the pessimistic hypothesis about aid's impact on recipient political institutions is likely overly pessimistic. It does not seem reasonable to think that additional aid, in any recipient government's hands, will have this effect. More democratic recipient 
countries have in place stronger separations of power and more effective checks on executive power. In these nations, it is unlikely that aid will have a centralizing effect on political institutions. The stronger checks on executive power in such countries means that political institutions are in place that tend to militate against the very sort of increased rent-seeking and consolidation-of-power forces foreign aid may bring into operation in the absence of such checks on executive authority. The more decentralized political institutions in these recipient countries helps to ensure that aid resources are in fact devoted more closely along the lines envisaged by donors. To this extent, additional foreign aid can be productively used by democratic recipient nations, which through the mechanisms discussed above identified by Knack (2004), can operate to make democratic recipients more democratic.

Together, these arguments point to a third, hybrid hypothesis about the effect of foreign aid on recipient political institutions. In recipient countries that have relatively decentralized political institutions, i.e., democracies, aid will have a democracy-enhancing effect. In recipient countries that have relatively centralized political institutions, i.e., dictatorships, aid will have a dictatorial-enhancing effect. In short, both democracies and dictatorships will tend to use aid in ways that promote the existing political institutional regime. For democracies, this means aid will lead to greater democracy; for dictatorships, this means aid will tend to lead to greater dictatorship. We call this hypothesis the amplification effect.

The amplification effect hypothesis suggests a more modest impact of aid on recipientcountry political institutions than either the optimistic or pessimistic hypotheses discussed above. Aid, in this view, does not have the power to fundamentally redirect the institutional trajectory of recipient countries. Its impact on recipient-nation political institutions is constrained to one that amplifies, or strengthens, existing political institutions. In what follows, we investigate the amplification effect hypothesis and in doing so also explore evidence for the existing hypotheses about aid's impact on political institutions, which we have called the optimistic and pessimistic views respectively. To do this, we use econometric analysis to isolate the effect of foreign aid on the extent of centralization, or democracy/dictatorship, 
in recipient countries' political institutions.

\section{Data and Empirical Strategy}

\subsection{Data}

To investigate the effect of foreign aid on political institutions we estimate a panel that covers 73 from 1975 to 2003. Data for our variables of interest come from two sources. We measure how much foreign aid a country receives in each year by the net official development assistance (ODA) plus official aid it receives as a percentage of its GNI. This includes grants and loans made on concessional terms to promote economic development and welfare (net of repayments of principle), excluding assistance for military purposes, by multilateral institutions and official donor agencies. This ratio is computed using values in U.S. dollars converted at official exchange rates. These data are from World Development Indicators (2005).

To measure how democratic or dictatorial countries' political institutions are-countries' political decentralization-we use data from the Polity IV project (2004). This measure ranges from -10, complete political centralization or "total dictatorship," to +10 , complete political decentralization or "total democracy." A score of zero means that a country is "institutionally undecided" in its political regime type, i.e., equal parts democracy and dictatorship. We call countries with scores greater than zero "democratic" and those with scores less than zero "dictatorships." Of course, both democracies and dictatorships come in different strengths. Our +10 to -10 scale captures this.

To measure the extent of democracy/dictatorship across countries, the Polity IV data considers the presence of political institutions and procedures through which citizens can express effective preferences about alternative policies and leaders, the existence of institutionalized constraints on the exercise of power by the executive, and the guarantee of civil liberties to all citizens in their daily lives and in acts of political participation. The resulting 
measure of political decentralization captures the competitiveness of political participation, openness and competitiveness of executive recruitment, and constraints on the chief executive in each country.Polity IV has constructed a variable to measure these factors specifically for the purpose of time series analysis, which makes each country's political decentralization score comparable over time. We use this measure, called Polity 2, for our examination. It covers the same years as our aid data, 1975-2003. Previous literatures have identified several other variables that may be important in determining countries' political institutions. We use these variables as controls in our analysis to isolate the impact of foreign aid on countries' political regimes. As noted above, natural resources, for example, have been cited a potentially important contributor to the degree of centralization in nations' political institutions (see, for instance, Djankov et al. (2008)). To account for this, we use the standard measure of natural resource dependence in the literature that examines the natural resource curse, natural resource exports as a share of GDP in 1970. Our data for this variable are from Sachs and Warner (1997).Previous work has also pointed to ethnic diversity as a potentially important determinant of countries' political institutions (see, for instance, Easterly and Levine 2001). To account for this we use each country's ethnolinguistic fractionalization measure, which calculates the probability that two randomly-drawn individuals from a country's population will be from different ethnolinguistic groups. This variable is from Philip G. Roeder's (2001) ELF dataset.Finally, we want to control for the initial extent of democracy/dictatorship in each country. To do this we again use data from Polity IV, in this case to construct an independent variable that measures the initial extent of political decentralization in each country, which for our sample is countries' degree of democracy/dictatorship in 1975.

\subsection{Empirical Specification}

Our basic empirical strategy for estimating the effect of foreign aid on developing countries' political institutions is straightforward. We want to examine the how foreign aid received by a country in one period interacts with the extent of democracy/dictatorship in its political 
institutions in the previous period to influence the extent of democracy/dictatorship in a country in the present. To do this, we need to construct an interaction term that multiplies aid received by a county in time $t$ with its political institutions in time $t$ - 1 to predict our dependent variable, political institutions in $t$. This interaction-term approach is the same one Burnside and Dollar (2000) use to study aid's effect on growth.

There is a significant problem with this basic specification, however, which is the same one confronted by all studies that seek to investigate the impact of foreign aid on various political and economic elements in developing countries. Namely, foreign aid is very likely to be endogenous. If the stated intent of donor agencies and countries can be taken at face value, which as discussed previously, includes "democratizing" developing countries,, greater aid flows to those countries with more dictatorial political institutions.

Fortunately, the literature that looks at foreign aid has developed an effective instrumental variables strategy for dealing with this problem. Our empirical model uses the same Two-Stage Least Squares (2SLS) strategy, which instruments foreign aid with the logarithm of countries' incomes at the beginning of the sample period (in our case, 1975), the logarithm of population in each country in 1975, and a group of variables that capture donors' strategic interests in giving aid. These include binary variables equal to one when a country is located in Sub-Saharan Africa, the Franc Zone, if it is a Central American country, or if it is Egypt, and zero otherwise. These are the same instruments for foreign aid that Burnside and Dollar (2000), Easterly et al. (2001) Djankov et al. (2008) use in previous studies.

To estimate the overall effect of foreign aid on political institutions, we begin with the following 2SLS model using our panel of 73 countries for the years from 1975-2003:

$$
\begin{aligned}
\text { Aid }_{i t} & =\alpha_{1}+\alpha_{2} Y_{i}+\alpha_{3} P_{i}+\alpha_{4} \text { Dummies }_{i}+\alpha_{5} X_{i t}+\varepsilon_{i t} \\
\text { Decentralization }_{i t} & =\beta_{1}+\beta_{2} \text { Decentralization }_{i t-1}+\beta_{3} \text { Aid }_{i t}+\epsilon_{i t}
\end{aligned}
$$


Equation (1) is the first stage of our 2SLS procedure, where $A i d_{i t}$ is our regressand and measures country i's ODA/GNI in time t. $\left.Y_{(} i\right)$ denotes 1975 income figures and $\left.P_{(} i\right)$ denotes 1975 population figures. Our independent variables in this equation are our instruments for aid discussed above, which include countries' initial income, initial population, and a variable that captures donor countries' strategic interests. Xi a vector of covariates that also affect political countries' political decentralization, which includes ethnolinguistic fractionalization, natural resource dependence and the initial extent of democracy/dictatorship in each country, which is their political decentralization scores in $1975 . \varepsilon_{i t}$ is a random error term.

Equation (2) is the second stage of our 2SLS procedure. It uses instrumentalized aid to estimate aid's effect on recipient countries' political institutions. Decentralization ${ }_{i t}$ is our regressand, which measures the extent of democracy/dictatorship in country i at time t. Our regressor of interest is the interaction term, $A i d_{i t} *$ Decentralization $_{i t-1}$, which measures how political institutions in country $\mathrm{i}$ at time $\mathrm{t}-1$ interact with the aid it receives in $\mathrm{t}$ to affect country i's political institutions in t. Interpreting the coefficient on our variable of interest, $? 2$, is straightforward. If aid enhances democracy in democratic countries and dictatorship in dictatorial countries, this term should be positive and significant. If aid enhances democracy in dictatorships and dictatorship in democracies, it should be negative and significant. $\mathrm{Xi}$ is a vector of covariates that includes countries' initial (1975) political decentralization scores, ethnolinguistic fractionalization, and natural resource dependence. $\epsilon_{i t}$ is a random error term.

The 2SLS model above estimates the effect of foreign aid on the levels of democracy/dictatorship in recipient countries. Equally important to consider is aid's impact on changes in democracy/dictatorship in recipient nations. We consider an alternative specification. In this model, everything is the same as above, only our dependent variable is now the change in recipient countries' political decentralization between $t-5$ and $t$. We consider the change in countries' democracy/dictatorship over five year periods because this allow sufficient time for the effect of aid on recipients' political decentralization to occur without being so long that 
it substantially shortens our panel. Our independent variable of interest remains the interaction term that multiplies aid received by country $i$ in time $t$ by its political decentralization in $t-1$.

\section{Benchmark Results}

\subsection{Benchmark Results for Levels}

The first column in Table 3.1 presents the second stage results of our initial regressions that consider the effect of foreign aid on the levels of democracy/dictatorship in recipient countries. Although we do not report our first-stage results, consistent with other studies that use the same instruments we do for aid, our instruments are strong and valid. The F-statistic is large $(\mathrm{F}=108.91)$, and the $\mathrm{R}$-squared is reasonable (0.34). Only the dummy for countries in Central America is insignificant.

In column 1 , the coefficient on our variable of interest, Aid $_{i t} *$ Decentralization $_{i t-1}$, is positive and significant. To interpret what this means for how aid impacts recipients' political institutions we need to take the partial derivative of equation (1) with respect to aid. Setting the equation equal to zero allows us to find the "critical democracy/dictatorship value," the level of existing recipient democracy/dictatorship at which aid exerts no impact on recipient political decentralization. Doing this delivers a critical political decentralization score of $(-0.08 / 0.08=)-1.00$.

Countries that are more democratic than this (those with political decentralization scores $>-1.00)$ become more democratic with additional foreign aid. Countries that are more dictatorial than this (those with political decentralization scores $<-1.00$ ) become more dictatorial with additional aid. Importantly, the critical democracy/dictatorship value is remarkably close to zero. Virtually all democracies become more democratic with additional aid, and virtually dictatorships become more dictatorial with more aid. Aid's impact then seems to be not one of reversing a country's previous institutional path but instead simply 
amplifying the institutional path that countries are already on.

We further investigate this amplification effect by examining the impact of foreign aid on recipients' political institutions when these institutions are decomposed into subgroups that correspond to the strength of democracy/dictatorship across countries. First, we consider groups of three so that countries with institutional decentralization scores of $-10,-9$, and -8 form one group, those with scores of $-7,-6$, and -5 for a second group, and so on for all possible scores so that there are seven groups ranging from the most dictatorial to the most democratic. For each group we construct separate interaction term, $\operatorname{Aid}_{i t} * D_{j, i t-1}$, which replaces our previous variable of interest, where $A i d_{i t}$ is the same as before and $D_{j, i t-1}$ is a binary variable for group j equal to one when country i's political institution score is one of the three institutional scores that correspond to group j and zero otherwise. Second, we decompose these groups further, breaking countries by political institutional regimes into subgroups of two. Thus, the most dictatorial group has scores of -10 or -9 . The second most dictatorial group has scores of -8 or -7 , and so on through the entire range, creating a total of 11 groups.

Decomposing the sample into these subgroups allows us to explore aid's impact on countries' political institutions in a detailed manner. We are able to see, for instance, if the amplifying effect identified in Table 3.1 holds true at all "degrees" of democracy/dictatorship, or if instead some strengths of democracies, for instance, are benefited by aid while other strengths of democracies are harmed by aid, and likewise for different strengths of dictatorships. Additionally, this decomposed analysis of aid's impact on political institutions allows us to get a closer look at the critical political decentralization value to see if, as suggested by the results in column 1 , the tipping point of aid's direction of effect on recipients' political decentralization is close to zero, or if instead, some, or most dictatorships become more democratic with additional foreign aid, or some, or most democracies become more dictatorial with additional aid, cutting against the amplification effect in column 1.

Column 1 of Table 3.2 presents the results of these regressions when political institutions 
are broken into groups of three. The estimates uniformly confirm the amplification effect from column 1. The first three groups, which cover all forms of non-marginal dictatorship from the strongest to the weakest (political institution scores of -10 through -2) all have negative and significant coefficients. Consistent with our previous finding, when dictatorships receive aid, they become more dictatorial. Furthermore, the more dictatorial the grouping, the larger is aid's negative effect on the recipient's political decentralization. As one moves from the most dictatorial grouping with the non-marginal dictatorships to the least dictatorial grouping within the dictatorships, aid's dictatorship-enhancing effect grows smaller. Aid enhances dictatorship in a country that is in the most dictatorial group 2.99 times more than it does in a country in the third-most dictatorial group.

The next four groups, which cover marginal democracies/dictatorships and all forms of non-marginal democracies (political institution scores of -1 through 10) all have positive and significant coefficients. When democracies receive aid, they become more democratic. Like for the dictatorships, as one moves from the strongest democratic grouping with the non-marginal democracies to the least democratic grouping within the democracies, aid's democracy-enhancing effect grows smaller. Aid enhances democracy in a country that is in the most democratic group 2.63 times more than it does in a country in the marginallydemocratic group. Of particular interest is the fourth group, which contains marginal dictatorships (scores of -1), institutionally "undecided" regimes (scores of 0), and marginal democracies (scores of +1 ). This group constitutes the tipping point at which aid's effect on political decentralization goes from negative among non-marginal dictatorships, to positive. Notably, aid's impact on undecided regimes is insignificant and substantially smaller than its impact on decidedly democratic or dictatorial regimes. Thus, the critical democracy/dictatorship value in terms is again nearly right in the middle of the democracy/dictatorship spectrum. Countries that are more dictatorial than those in the undecided group become more dictatorial with more aid. Countries that are more democratic than those in the undecided group become more democratic with more aid. 
Figure 1 illustrates the amplification effect graphically. Using our estimates from column 2 it depicts the predicted effect of additional foreign aid on recipient countries' political decentralization by their current level of political decentralization. Each bar depicts the predicted impact of additional aid for each of the different political decentralization groupings column 2 considers.

The three left-most bars capture the dictatorships. The middle bar represents the undecided group. The three right-most bars capture the democracies. For each of the dictatorship groups, the impact of additional aid on political decentralization is negative. More aid makes dictatorships more dictatorial. Here it is easy to see that aid's dictatorship-enhancing effect on stronger dictatorships is larger than for weaker dictatorships. Aid's impact on the undecided group, in contrast, is nearly zero. Moving to the democracies, for each of the democratic groups, aid enhances their political decentralization, making them more democratic. And, like for dictatorships, aid's democracy-enhancing effect is larger for stronger democracies than it is for weaker ones. Figure 1 clearly shows that aid's impact on recipients' political institutions is only one of amplifying existing regime types rather than reversing their institutional trajectory. Notably, aid's helpful (democracy-enhancing) effect for democratic regimes appears to be larger than aid's harmful (dictatorship-enhancing) effect for dictatorial regimes.

Column 1 in Table 3.3 presents our results when institutional regimes are broken into groups of two. Each "dummy group" contains two political decentralization scores, with the exception of one group which contains only the political decentralization score of zero, the institutionally "undecided" group, for a total of 11 groupings. This more refined division further substantiates the amplification effect. The coefficients on the first five groups, which cover institutional score ranging from -10 to -1-all dictatorships-are negative and, in all cases but one, significant. When dictatorships receive aid, they become more dictatorial. The coefficients on the last five groups, which cover institutional scores ranging from +10 to +1-all democracies-are positive and significant. When democracies receive more aid, they 
become more democratic. Also like our estimates, the magnitude of aid's effect on political institutions corresponds directly to the strength or weakness of the political regime in question. Thus, the strongest dictatorial group experiences the largest dictatorship-enhancing effect of foreign aid among the dictatorships, with the strength of this effect diminishing as the strength of the dictatorship in question diminishes. Similarly, the strongest democratic group experiences aid's largest democracy-enhancing effect among the democracies, with this effect's strength (in all cases but one) diminishing as the strength of the democracy diminishes. Of special interest here is the sixth group, the institutionally undecided regimes with political decentralization scores of zero. Starting from the most dictatorial regimes and moving toward the democratic regimes, this is the first group for which aid's effect on political decentralization becomes positive. Similar to in column 2, aid's effect on these undecided regimes is small relative to its effect on decidedly democratic or dictatorial regimes. Consistent with our previous results, this group constitutes the tipping point of aid's effect on recipients' political decentralization. In Figure 2 we present the same graphical analysis as in Figure 1, only here we consider countries broken down into groups of political decentralization scores of two and use our estimates from column 3 to illustrate aid's effect on political institutions. The pattern is the same as in Figure 1. Aid negatively impacts all dictatorships making them more dictatorial, and increasingly so the stronger the dictatorship was to begin with. In contrast, aid positively impacts all democracies making them more democratic, and increasingly so the stronger the democracy was to begin with. Aid's impact on the undecided group's political decentralization is again positive but very small. Also like before, aid's democracy-enhancing effect on democratic regimes is larger than its dictatorship-enhancing effect on dictatorial regimes.

\subsection{Changes in Political Decentralization}

Table presents the results of our change model in equations (3) and (4). These results make clear that the amplification effect holds when looking at aid's impact on changes in recipients' 
political decentralization changes in addition to levels.

Column 2 of Table 3.1 contains our default specification. The results are nearly the same as those in the regressions that looked at levels. The coefficient on our interaction term, which here measures the impact of aid on changes in democracy/dictatorship, is positive and significant. Most importantly, the critical political decentralization value remains about the same, nearly zero. Here, this value is -0.33. Nearly all dictatorships-countries with political decentralization scores less than zero-experience a pro-dictatorship change in their political regime as the result of additional foreign aid. All democracies, in contrast, countries with political decentralization scores greater than zero, experience a pro-democracy change in their political regime as the result of additional aid. In column 2 of Table 3.2 we break our sample down by regime type into groups of three, as we did before. Our results are again nearly identical. The three dictatorship groups all have negative coefficients. Only one group (the weakest dictatorships) is insignificant. For dictatorships, additional aid leads to a pro-dictatorial change in their political institutions. All three democratic groups have positive and significant coefficients. For them, additional aid leads to pro-democratic changes in their political institutions. Of special interest again is the fourth group, which contains marginal dictatorships, totally undecided regimes, and marginal democracies. Here, the impact of additional aid is positive, but insignificant and nearly zero. Finally, in column 2 of Table 3.3 we break our political regime groupings down another level into groups of two, as we did in Table 1 when looking at levels. Again, our results are virtually unchanged. All dictatorships experience pro-dictatorial changes in their political regimes as the result of aid. The first grouping that experiences a positive change in their political regime as a result of additional aid is the undecided group, which here contains only totally undecided regimes (those with political decentralization scores of zero) for whom the effect of aid, while positive, is small compare to aid's impact on decidedly democratic and dictatorial regimes. With one exception, all democracies experience a positive change in their political regime as a result of more foreign aid. This single exception is the weak democracy grouping with political 
decentralization scores of one and two, which has a negative but insignificant coefficient.

\section{Robustness}

We take a number of steps to ensure the robustness of our findings. First, in addition to looking at aid's impact on recipient countries' political decentralization in both levels and changes at the aggregate, partially-disaggregated, and further-disaggregated level, we also try rerunning all of our regressions in Tables and using a simple dummy for dictatorships, any county with a negative political decentralization score. Table presents these results, which are virtually unchanged. Additional foreign aid leads dictatorial regimes to become more dictatorial looking at both levels and changes in political decentralization.

Next, we try rerunning all of our regressions controlling for illiteracy in each country to see if this affects our results. It does not. Table presents our estimates for these regressions, which are virtually unchanged. Additional aid makes dictatorships more dictatorial and democracies more democratic. The critical political decentralization value above which aid helps nations' political regimes and below which it harms them falls slightly but remains close zero. In the regressions that look at levels, the critical political decentralization value falls to about -2.5. In our regressions that look at changes it falls to approximately -1.3. These scores represent the weakest of dictatorships. In these specifications, any country that is more dictatorial than this becomes more dictatorial with additional aid and vice versa. The amplification effect is strong and consistent.

Third, we re-estimate all of our regressions using a panel that includes a larger number of years. First, we try a panel that covers the years 1970-2003. Second, we try a panel covering the years from 1965-2003. Because of data limitations, the further back our panel goes the fewer countries it includes. Our findings, however, are consistent. Regardless of the years our panel covers, the amplification effect is robust. Using both the 1970-2003 panel and the 1965-2003 panel, in both the levels and changes models, the critical political decentralization 
value is close to zero. Aid makes democracies more democratic and makes dictatorships more dictatorial. When we decompose countries into subgroups groups by regime type we also find the same results as before. Aid negatively affects dictatorships' political institutions, positively affects democracies' political institutions, and 'tips' from having a negative to a positive impact on recipient countries' political institutions for politically-undecided regimes.

Finally, we try rerunning all of our regression using an alternative measure of foreign aid to see if this influences our results. Instead of using each country's ODA as a percentage of its GNI we try using each county's foreign aid per capita. When we use aid per capita, our results change slightly but remain fundamentally similar. In our regressions that look at levels of political decentralization, the new critical value rises slightly to about 1.34, the political decentralization score of very weak democracies. Countries more democratic than this become more democratic with additional aid. Countries less democratic than this become less democratic with additional aid.

This slightly higher tipping point for the direction of aid's impact is corroborated in our regressions that look at aid's effect on political decentralization by regime type. The first political regime grouping for which aid has a democracy-enhancing effect becomes the weakest democracies rather than the undecided regimes, as in our regressions that use ODA/GNI to measure aid. In our regressions that look at aid's impact on changes in recipients' political decentralization we find the same modest increase in the critical value for aid. Weak democracies and regimes that are more democratic than this become more democratic with additional aid. All dictatorships and the weakest democracies become more dictatorial with additional aid.

\section{More Robustness}

We test the robustness of our findings by alternative model specification. In the alternative model, we consider five year averages of the entire sample period 1975 to 2003. Then we 
rerun our results by constructing separate dummies for dictatorships and democracies. Thus, we consider the whole sample and run separate regressions each time with dummies of dictatorship sample and dummies of democracy sample. Aid is interacted with the dummy. We control for the same set of control variables except decentralization of starting period. Instead, we include the variables decentralization lagged one period and decentralization lagged two period.We expect the coefficient of aid interacted with the dummy for dictatorships to be negative and the other coefficient to be positive. The results of our benchmark specification with the alternative model shows that the interaction coefficient is,indeed, negative for dictatorship sample and positive for democracy sample. Thus, the results, further, establish the robustness of our findings that if the aid-recipient country has autocratic institutions, then, greater aid inflows will, further, degrade the quality of political institutions. But, if the aid-recipient country has institutions which are democratic in nature, then receiving more aid will lead to the betterment of those institutions.

We check the robustness of the alternate specification by controlling for illiteracy rate, population and gross domestic product. The results remain unaffected. Further, we check the robustness of the results by considering changes in decentralization as the dependent variable rather than levels of decentralization. Our conclusions remain unchanged. Finally, we also run panel regressions by adopting a random effect model and the results remain unaffected.

\section{Conclusion}

The results of our analysis lead to several conclusions. First, both the optimistic view of aid's impact on recipient countries' political institutions, which tends to see aid as a magic elixir that can make dictatorships more democratic, and the pessimistic view of aid, which sees aid as a potent poison that makes weakens democracy in recipient countries overstate the ability of aid to do good or bad. Our findings suggest that aid does not have this kind 
of institutional-trajectory reversing power for democracies or dictatorships.

Instead, we find evidence for a more modest impact of aid on recipients' political institutions, which amplifies or reinforces the trajectory of political institutions that developing nations are already on. Aid makes virtually all already democratic countries more democratic and virtually all already dictatorial countries stronger dictatorships, but it does not fundamentally affect the underlying regime type of developing nations.

Second, our results suggest that a reorientation of current views on the ability of aid to help or harm developing recipient countries' political institutions may be required. Although it is true that giving additional aid to already democratic nations will not, it seems, lead to greater political centralization, as the critics of aid sometimes suggest, more importantly, it appears that aid for the purposes of democratizing the politically-centralized developing world not only fails to achieve its goals but in fact does significant harm to these aid recipients. Supplying additional aid to dictatorships with the hopes of transforming them into democracies tends to have the reverse effect, actually leading to greater political centralization in these countries.

Third, our results suggest a possible mechanism at work that helps to explain Burnside and Dollar's (2000) finding that aid promotes growth in countries that pursue good policies, but fails to do so in countries that do not. To the extent that because of their stronger constraints on executive power democracies tend to pursue better economic policies than dictatorships, when democracies receive foreign aid they become more democratic, leading to the adoption of better policies, which in turn leads to higher economic growth. Conversely, when dictatorships receive aid they become more dictatorial, preventing the adoption of better policies, which in turn prevents increases in economic growth.

Finally, our results suggest that aid exerts almost no impact on the political institutions of recipient countries with undecided regimes. This finding is sobering from the perspective of development policy. Undecided political regimes are those that have not yet committed to an institutional path of democracy or dictatorship. Presumably, it is precisely these regimes 
the development community is most eager to tip in the democratic direction. Unfortunately, however, it is precisely for these regimes that foreign aid's power to affect institutional change is most neutered. 
Table 3.1: The Impact of Foreign Aid on Political Decentralization(Both levels and changes)

\begin{tabular}{|c|c|c|c|c|}
\hline Variables & $\begin{array}{c}(1) \\
\text { decentralization }\end{array}$ & $\begin{array}{c}(2) \\
\Delta \text { decentralization }\end{array}$ & $\begin{array}{c}(3) \\
\text { decentralization }\end{array}$ & $\begin{array}{c}(4) \\
\Delta \text { decentralization }\end{array}$ \\
\hline Aid & $\begin{array}{c}0.0775 \\
(0.0994)\end{array}$ & $\begin{array}{l}0.00576 \\
(0.0396)\end{array}$ & $\begin{array}{c}0.196 \\
(0.117)\end{array}$ & $\begin{array}{c}0.0414 \\
(0.0460)\end{array}$ \\
\hline Initial Decentralization & $\begin{array}{l}0.356^{* * *} \\
(0.0635)\end{array}$ & $\begin{array}{c}-0.194^{* * *} \\
(0.0234)\end{array}$ & $\begin{array}{c}0.346^{* * *} \\
(0.0646)\end{array}$ & $\begin{array}{c}-0.195^{* * *} \\
(0.0204)\end{array}$ \\
\hline Fractionalization & $\begin{array}{l}1.250 \\
(1.093)\end{array}$ & $\begin{array}{c}0.335 \\
(0.407)\end{array}$ & $\begin{array}{l}2.017^{*} \\
(1.145)\end{array}$ & $\begin{array}{c}0.493 \\
(0.407)\end{array}$ \\
\hline Resource Abundance & $\begin{array}{c}-6.061^{* * *} \\
(1.767)\end{array}$ & $\begin{array}{c}-1.861^{* * *} \\
(0.684)\end{array}$ & $\begin{array}{c}-5.816^{* * *} \\
(1.931)\end{array}$ & $\begin{array}{c}-1.880^{* * *} \\
(0.645)\end{array}$ \\
\hline Aid*Decentralization & $\begin{array}{c}0.0840^{* * *} \\
(0.0101)\end{array}$ & $\begin{array}{l}0.0277^{* * *} \\
(0.00401)\end{array}$ & $\begin{array}{l}0.0820^{* * *} \\
(0.00940)\end{array}$ & $\begin{array}{l}0.0295^{* * *} \\
(0.00491)\end{array}$ \\
\hline Illiteracy & & & $\begin{array}{c}-0.0598^{* * *} \\
(0.0173)\end{array}$ & $\begin{array}{l}-0.0145^{* *} \\
(0.00590)\end{array}$ \\
\hline $\begin{array}{l}\text { Observations } \\
R^{2}\end{array}$ & 1871 & 1603 & 1703 & 1459 \\
\hline$R^{2}$ & 0.668 & 0.108 & 0.697 & 0.116 \\
\hline
\end{tabular}

For columns 1 and 2, the regressand is level of polity whereas for columns 3 and 4 , the regressand is changes in polity. In columns 3 and 4 , we control for illiteracy. 
Table 3.2: The Impact of Foreign Aid on Political Decentralization(Both levels and changes)

\begin{tabular}{|c|c|c|}
\hline Variables & $\begin{array}{c}(1) \\
\text { decentralization }\end{array}$ & $\begin{array}{c}(2) \\
\Delta \text { decentralization }\end{array}$ \\
\hline D1*Aid & $\begin{array}{c}-0.708^{* * *} \\
(0.173)\end{array}$ & $\begin{array}{c}-0.248^{* * *} \\
(0.0664)\end{array}$ \\
\hline $\mathrm{D} 2 *$ Aid & $\begin{array}{c}-0.489^{* * *} \\
(0.142)\end{array}$ & $\begin{array}{c}-0.252^{* * *} \\
(0.0741)\end{array}$ \\
\hline D3*Aid & $\begin{array}{c}-0.242^{* *} \\
(0.104)\end{array}$ & $\begin{array}{l}-0.111 \\
(0.0691)\end{array}$ \\
\hline $\mathrm{D} 4^{*}$ Aid & $\begin{array}{c}0.0702 \\
(0.0556)\end{array}$ & $\begin{array}{l}0.00832 \\
(0.0432)\end{array}$ \\
\hline D5*Aid & $\begin{array}{c}0.349^{* *} \\
(0.141)\end{array}$ & $\begin{array}{c}0.431^{* *} \\
(0.202)\end{array}$ \\
\hline D6*Aid & $\begin{array}{c}0.607^{* * *} \\
(0.125)\end{array}$ & $\begin{array}{c}0.338^{* * *} \\
(0.0913)\end{array}$ \\
\hline $\mathrm{D} 7^{*}$ Aid & $\begin{array}{c}0.924^{* * *} \\
(0.246)\end{array}$ & $\begin{array}{c}0.234^{* * *} \\
(0.0865)\end{array}$ \\
\hline Initial Decentralization & $\begin{array}{c}0.365^{* * *} \\
(0.0613)\end{array}$ & $\begin{array}{c}-0.196^{* * *} \\
(0.0259)\end{array}$ \\
\hline Fractionalization & $\begin{array}{c}0.997 \\
(1.060)\end{array}$ & $\begin{array}{c}0.194 \\
(0.442)\end{array}$ \\
\hline Resource Abundance & $\begin{array}{c}-5.659^{* * *} \\
(1.853)\end{array}$ & $\begin{array}{c}-1.866^{* *} \\
(0.709)\end{array}$ \\
\hline $\begin{array}{l}\text { Observations } \\
R^{2}\end{array}$ & $\begin{array}{l}1939 \\
0.721\end{array}$ & $\begin{array}{l}1605 \\
0.185\end{array}$ \\
\hline
\end{tabular}


Table 3.3: The Impact of Foreign Aid on Political Decentralization(Both levels and changes)

\begin{tabular}{|c|c|c|}
\hline Variables & decentralization & $\Delta$ decentralization \\
\hline D1*Aid & $\begin{array}{c}-0.604^{* * *} \\
(0.146)\end{array}$ & $\begin{array}{c}-0.226^{* * *} \\
(0.0525)\end{array}$ \\
\hline D2*Aid & $\begin{array}{c}-0.593^{* * *} \\
(0.118)\end{array}$ & $\begin{array}{c}-0.318^{* * *} \\
(0.0743)\end{array}$ \\
\hline D3*Aid & $\begin{array}{c}-0.384^{* *} \\
(0.159)\end{array}$ & $\begin{array}{c}-0.198^{* *} \\
(0.0816)\end{array}$ \\
\hline D4*Aid & $\begin{array}{c}-0.321^{* * *} \\
(0.0982)\end{array}$ & $\begin{array}{l}-0.0932 \\
(0.0784)\end{array}$ \\
\hline D5*Aid & $\begin{array}{l}-0.0736 \\
(0.0829)\end{array}$ & $\begin{array}{l}-0.103^{*} \\
(0.0546)\end{array}$ \\
\hline D6*Aid & $\begin{array}{c}0.0835^{* *} \\
(0.0391)\end{array}$ & $\begin{array}{l}0.0732^{*} \\
(0.0430)\end{array}$ \\
\hline D7*Aid & $\begin{array}{c}0.270^{* *} \\
(0.108)\end{array}$ & $\begin{array}{l}-0.137 \\
(0.160)\end{array}$ \\
\hline D8*Aid & $\begin{array}{c}0.405^{* *} \\
(0.195)\end{array}$ & $\begin{array}{l}0.649^{*} \\
(0.327)\end{array}$ \\
\hline D9*Aid & $\begin{array}{c}0.683^{* * *} \\
(0.0990)\end{array}$ & $\begin{array}{c}0.299^{* *} \\
(0.127)\end{array}$ \\
\hline D10*Aid & $\begin{array}{c}0.641^{* * *} \\
(0.179)\end{array}$ & $\begin{array}{c}0.316^{* *} \\
(0.127)\end{array}$ \\
\hline D11*Aid & $\begin{array}{c}1.250^{* * *} \\
(0.305)\end{array}$ & $\begin{array}{l}0.179^{* *} \\
(0.0874)\end{array}$ \\
\hline Initial Decentralization & $\begin{array}{c}0.352^{* * *} \\
(0.0599)\end{array}$ & $\begin{array}{c}-0.199^{* * *} \\
(0.0273)\end{array}$ \\
\hline Fractionalization & $\begin{array}{l}1.281 \\
(1.064)\end{array}$ & $\begin{array}{c}0.307 \\
(0.485)\end{array}$ \\
\hline Resource Abundance & $\begin{array}{c}-6.282^{* * *} \\
(1.658)\end{array}$ & $\begin{array}{c}-1.979^{* *} \\
(0.747)\end{array}$ \\
\hline $\begin{array}{l}\text { Observations } \\
R^{2}\end{array}$ & $\begin{array}{l}1939 \\
0.731\end{array}$ & $\begin{array}{l}1605 \\
0.193\end{array}$ \\
\hline
\end{tabular}


Table 3.4: With Dummies for Dictatorships

\begin{tabular}{lcc}
\hline Variables & decentralization & Ddecentralization \\
\hline & & \\
D1*Aid & $-0.661^{* * *}$ & $-0.245^{* * *}$ \\
& $(0.161)$ & $(0.0696)$ \\
D2*Aid & $-0.367^{* * *}$ & $-0.232^{* * *}$ \\
& $(0.136)$ & $(0.0835)$ \\
D3*Aid & -0.0965 & -0.0776 \\
& $(0.131)$ & $(0.0831)$ \\
D4*Aid & $0.162^{*}$ & 0.0363 \\
& $(0.0826)$ & $(0.0537)$ \\
D5*Aid & $0.472^{* * *}$ & $0.375^{* *}$ \\
& $(0.169)$ & $(0.176)$ \\
Observations & 1765 & 1461 \\
$R^{2}$ & 0.746 & 0.196 \\
\hline
\end{tabular}

Robust standard errors in parentheses ${ }^{* * *} \mathrm{p}<0.01,{ }^{* *} \mathrm{p}<0.05,{ }^{*} \mathrm{p}<0.1$ 
Table 3.5: List of Countries

\begin{tabular}{|c|c|c|}
\hline Algeria & Guinea-Bissau & Panama \\
\hline Argentina & Guyana & Papua New Guinea \\
\hline Bangladesh & Haiti & Paraguay \\
\hline Benin & India & Philippines \\
\hline Bolivia & Indonesia & Rwanda \\
\hline Botswana & Iran & Saudi Arabia \\
\hline Brazil & Jamaica & Senegal \\
\hline Burkina Faso & Jordan & Singapore \\
\hline Burundi & Kenya & Solomon \\
\hline Cameroon & Korea, South & Sri Lanka \\
\hline Chad & Kuwait & Sudan \\
\hline Chile & Lesotho & Swaziland \\
\hline Colombia & Liberia & Syria \\
\hline Congo, Republic of & Madagascar & Thailand \\
\hline Costa Rica & Malawi & Togo \\
\hline Cyprus & Mali & Trinidad \\
\hline Dominican Republic & Mauritania & Tunisia \\
\hline Ecuador & Mexico & Turkey \\
\hline Egypt & Morocco & United Arab Emirates \\
\hline El Salvador & Nepal & Uruguay \\
\hline Fiji & Nicaragua & Venezuela \\
\hline Gabon & Niger & Zambia \\
\hline Gambia & Nigeria & Zimbabwe \\
\hline Ghana & Oman & \\
\hline Guatemala & Pakistan & \\
\hline
\end{tabular}


Table 3.6: Data Sources

\begin{tabular}{|r|r|}
\hline Variable & Description \\
\hline Aid & WDI (2005) \\
\hline Political decentralization & Polity IV Project (2004) \\
\hline Initial political decentralization & Polity IV Project (2004) \\
\hline Fractionalization & Roeder,(ELF) Indices, 1961 and 1985 (2001) \\
\hline Natural resources & Sachs and Warner(1997) \\
\hline Illiteracy & WDI (2005) \\
\hline Aid per capita & WDI (2005) \\
\hline
\end{tabular}


Figure 3.1: Aid's Impact on Political Decentralization by Regime Type (Groups of Two)

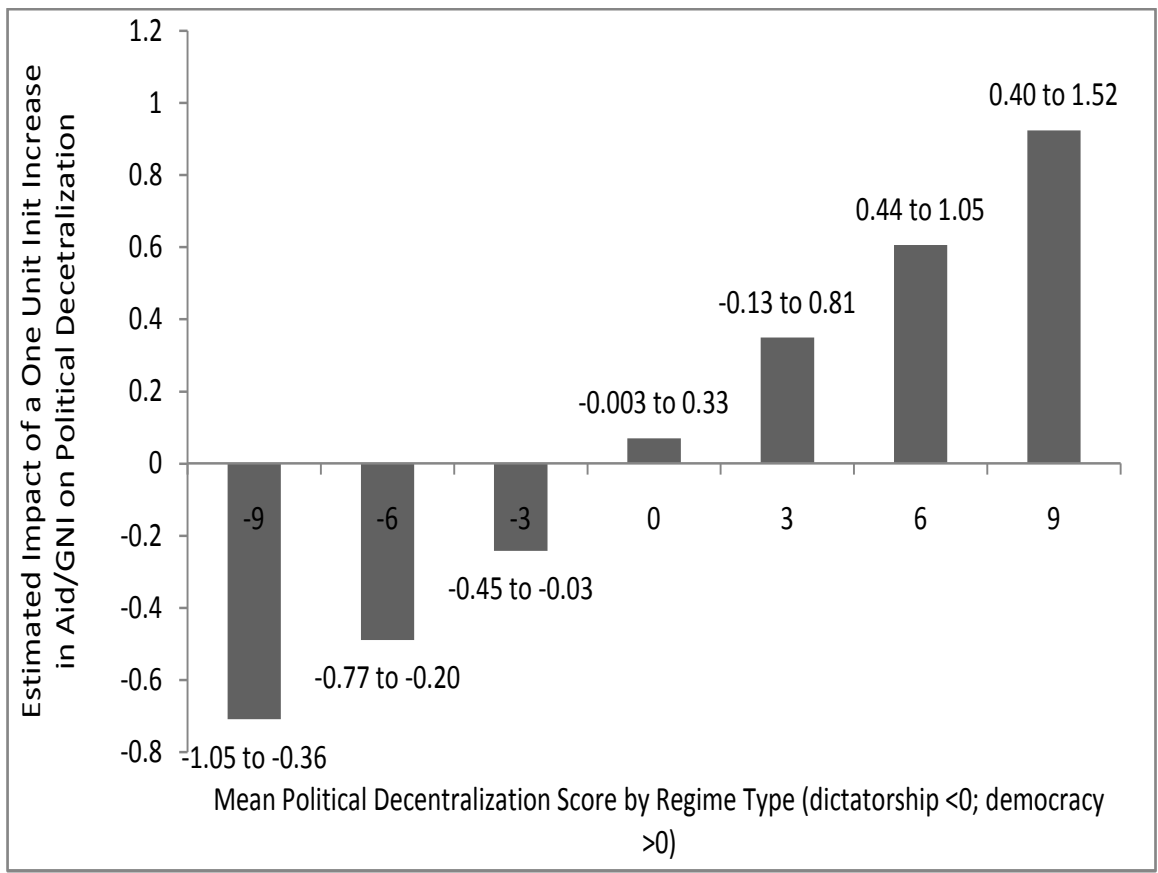

Note: The means for each group are mentioned inside the bars. The numbers below or above the bars represent the confidence interval for the corresponding t-coefficient of each group. 
Figure 3.2: Aid's Impact on Political Decentralization by Regime Type (Groups of Two)

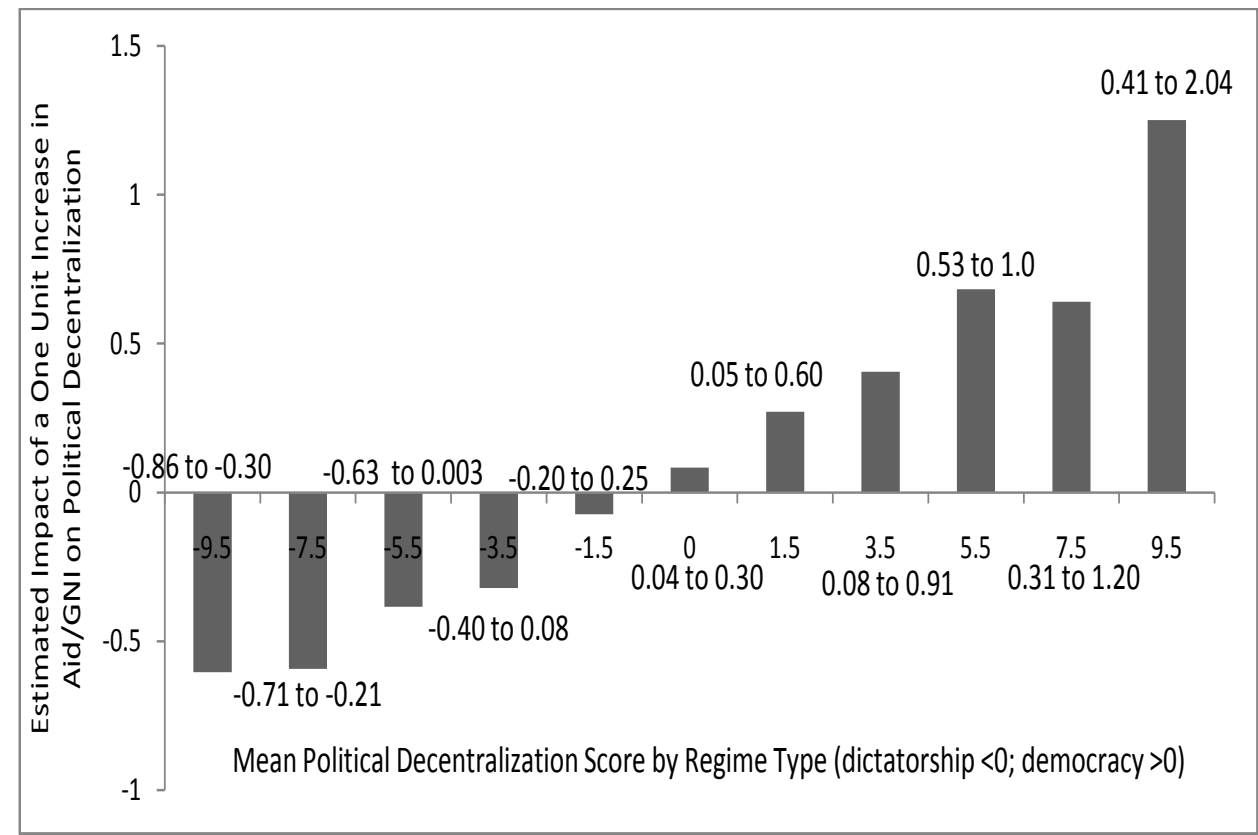

Note: The means for each group are mentioned inside the bars. The numbers below or above the bars represent the confidence interval for the corresponding t-coefficient of each group. 


\section{Chapter 4}

\section{Corporate Profit Tax, Formula}

\section{Apportionment, and Multinational}

\section{Firms}

\section{Introduction}

In the last two decades, one of the most talked about issue in the international arena is the rising trend of multinational activities all across the globe along with rise in foreign direct investment inflows. The growing mobility of capital and the concomitant importance of foreign direct investment have given a new meaning to capital tax competition. Recent literature has focused on tax competition between MNCs. Devereux and Griffith (1998) established effective marginal tax rates as an important determinant of choice location of foreign investors. It has also been found that a 1 percentage point reduction in the host country tax rates leads to an increase of 3.3 percent in foreign direct investment inflows (?).

While setting up multinational corporation, the firms make strategic choices regarding the location of their investment, production and profits. There is a huge literature which talks about the wide set of incentives which attract FDI to an economy. The greater availability 
of inexpensive labor, skilled workers, and production inputs are some of the many factors. One of the important factors in this respect is the taxation policy of the host country. The increasing trends of globalization along with rising importance of tax competition have raised the need for articulating effective national corporate income taxation policies. Among other debates regarding the impact of globalization on the growth and development of a nation, one of the main concerns of the policy makers is the trend of the multinational firms to shift profit from a high tax jurisdiction to a low tax jurisdiction. The European Commission has focused on policies so as to address the issue of profit shifting my multinational firms. One of their main proposals was that multinational firms should shift from the more commonly used Separate Accounting taxation system to Formula Apportionment tax regime.

Tax practitioners, economists and politicians are particularly concerned about the fact MNEs can shift activities as well as earnings from one location to another since it provides them with the incentive of moving larger shares to low tax bases. When a corporation has business activities established in multiple countries, the local authority can levy a tax on income generated on that location. But measuring the income earned within each region is a difficult conceptual issue. For instance, the corporate taxation in the European Union requires firms to maintain different accounts for its activities in each country where it operates. This system is called Separate Accounting (SA) where the subsidiaries act as distinct companies in the multiple locations.

The US and Canada, on the other hand, use a formula apportionment (FA) system which has been the focus of recent research. FA, as used in the US, asserts that the proportion of a multi-regional firm's income earned in a given state is a weighted average of the proportion of the firm's total sales, property, and payroll in that state. Thus, the firm's activities in a specific region are approximated by the share of these factors in the region. In other words, the firm is not required to keep different accounts. A key difference between SA and FA is that former curbs the incentives of the firms to engage in transfer pricing.Further,Mintz (2004) pointed out that FA leads to lower compliance costs. Yet, literature has identified that 
both tax systems distort product decision- SA does it through its income shifting effects while FA creates distortions through factor returns. SA and FA lead to different tax incentives for each country.

There is a wide array which has explored the issue of corporate taxation and transfer pricing under separate accounting (SA). Some papers have studied the optimal taxation policy under SA when firms shift profits from high tax jurisdiction to low tax jurisdiction (Haufler and Schjelderup, 2000). Under their set up, countries choose both tax rate and tax base. Konan (1996) has presented a model in her paper where multinational enterprises set prices on globally joint inputs. She finds in the paper that rather than taxing profits that have been domestically earned, the home-tax equilibrium solution is to tax foreign earned profits.

Mclure's (1980) paper is a major contribution in the SA vs. FA literature. He showed in his paper that government in different locations can encourage investment and employment within their own jurisdictions by altering the weights on the shares of capital, payroll and sales. The literature under FA tax regime discusses the different types of formula which need to be adopted by the particular region so as to create optimal tax equilibrium. In USA all the states have adopted a FA tax regime. According to Anand and Sansing (2000), if all 50 states follow the same apportionment formula, then more or less than 100 percent of a corporation's income can be subject to state income tax. The most traditional formula set up is the adoption of a three factor, equal weighted formula (EWF) system. In this case, all the shares - capital share, sales share and payroll share - are weighted equally. When the different states in USA adopted the FA tax regime, then they followed the EWF system.

Over the decades, almost two-thirds deviated from the standard system and most of them adopted a system where the sales factor is double weighted (DWSF). Anand and Sansing (2000) suggest in their paper that the choice between EWF and DWSF for the states depends on the desire of the states to tax immobile capital, such as agriculture and natural resources, rather than taxing mobile capital such as manufacturing. Some of the other important papers 
discussing the impact of taxation under FA system are Gordon and Wilson (1986), Gerard and Weiner (2003), Eggert and Schjelderup (2003), Eggert and Schjelderup (2005),Nielsen et al. (2003), Srenson (2004) and Pinto (2007).

Some papers have explored the welfare implications of a switch from SA to FA. Using an empirical framework based on a sample of US multinationals for the period 1989 -1993, Slemrod and Shackelford (1998) found in their paper that a switch from SA to FA would increase US tax liabilities by 38 percent if an equal three weighted, three factor formula is used. Further, Mintz (2004) pointed out that FA leads to lower compliance costs.

In this paper, we examine how political factors may shape the structure of the corporate profit tax in the presence of multinational corporations. There is a huge array of literature which tries to explore the advantages and disadvantages of SA and FA in terms of optimizing the objectives of corporate taxation policies. Yet, no study has explored the question that how the incentives of a multinational firm to operate in a location change when the local government tries to maximize the domestic welfare. In the case of Formula Apportionment regime, the specific formula used to allocate profits of multinational firms for tax purposes will affect the firm's incentive to operate in the country. As a result the choice of a particular formula will also end up having an impact on local consumers, local government and the multinational itself. The different formulas assign different weights to the capital, sales and labor shares of the multinational corporation. Suppose that the choice of the formula is the result of a political process. Which formula would then be chosen by governments representing the interests of domestic consumers, which one would be chosen to represent its own interest and which ones would be chosen to represent the interest of the multinational firm?

The government in respective locations will adopt policies that will maximize the welfare of different political groups. Suppose the government is concerned with the welfare of domestic consumers; then it will accordingly choose the policy which will maximize consumer surplus. For the present analysis, we are concerned with different taxation policies which 
are chosen under a FA tax regime. Accordingly as the government decides to implement different policies, the optimal formula will be chosen which will put certain weight to capital share and a certain weight to sales share. In response,the firms in different locations will react to different formulas by changing their allocation of capital and sales. The government's decision to implement policies domestically will depend on the extent of political influence of different groups to lobby for its welfare.

The main contribution of our paper is that it points out how the decision of the MNC firm to allocate capital and sales affects the price of the good in respective locations. Firms react to policies adopted by the government by changing their capital and sales shares and, this, in turn, affects the price of domestic goods. Though past research has looked into a vast number of theoretical models regarding the impacts of SA and FA regimes and the consequences of a switch from one to another, this particular aspect has not been looked into as yet. This is an important contribution to the literature because it suggests that the government of a particular country will have incentives to adopt a certain policies which, in

turn, will have the linkage effect on prices of domestic goods. If goods become too expensive, it will hurt the interest of the consumers which is not desirable for a country.

The next section of the paper sets up the model. Section 3 explores the properties of equilibrium and describes in detail the various stages of the game. It also elaborates on the intuition of the model by adopting a numerical example which illustrates the properties of the equilibrium in greater detail. Section 4 describes the main results of the paper and section 5 concludes.

\section{The Model}

Consider an economy with two regions or countries $a$ and $b$. A multinational corporation (MNC) has activities in both countries. The MNC in both locations produce the same good and it can transfer (at a cost) part of its production from one country and sell it in the other. 
Capital is the only factor of production. Output is produced using a CRS technology. Let $k^{i}$ denote the amount of capital employed by the domestic firm in $i, k^{i i}$ the level of capital in $i$ used by the MNC to produce the good that is sold in country $i$, and $k^{j i}$ the amount of capital used by the MNC in country $j$ to produce the good for consumers in $i$. Thus, the total number of units sold in location $i$ is given by $k^{i}=k^{i i}+k^{j i}$, for $i, j=a, b$ and $i \neq j$. For simplicity, the demand for the good in country $i$ is assumed to be linear. In particular, $p\left(k^{i}\right)=\alpha+\beta k^{i}$. $\alpha$ and $\beta$ are exogenously chosen parameters. Production costs are given by $c^{i}$. When the MNC produces in $j$ and sells in $i$ (i.e., $k^{j i}>0$ ), it faces a transportation $\operatorname{cost} \tau$ per unit shipped to $i$.

Domestic governments raise revenue by imposing a corporate profit tax on the MNC. As in Pinto (2007), capital expenses can only be imperfectly deducted from the firm's taxable income. Specifically, the tax base in country $i$ is the value of output minus a fixed share $\mu^{i}$ of the true capital cost, where $\mu^{i} \geq 0$ represents the proportion of capital expenses that can be deducted from taxable income. The deductibility of capital expenses can either be above or below its true costs. If a tax system allows only incomplete deduction of capital costs, then $\mu^{i}<1$, which means that a positive tax is also levied on capital. If $\mu^{i}=1$, the corporate tax falls only on pure profits, and when $\mu^{i}>1$, capital is subsidized, i.e., firms can deduct more than the true capital expenditures from taxable income. ${ }^{1}$

\subsection{Formula Apportionment}

Suppose that both regions adopt a formula apportionment (FA) method to calculate the share of the firms activities in each jurisdiction. Under this tax system, each country apportions the total taxable income of the MNC according to a given formula, which determines the proportion of the firm's total profits taxed by the country. Supposedly, the formula should capture the proportion of the overall activities of the MNC performed in the country. Our interest is on FA tax regimes that consider sales, property, or a combination of the two

\footnotetext{
${ }^{1}$ Our subsequent analysis will focus on the case where $\mu^{i}=0, i=a, b$.
} 
factors as proxies of the firms activities in each country.

Formally, the FA system can be described as follows. Let $\gamma^{i}$ denote the share of the MNC's activities in region $i$ as determined by the apportionment formula employed by the tax authority in that region. Then,

$$
\gamma^{i}=m^{k i} \alpha^{k i}+m^{s i} \alpha^{s i}, \quad i=a, b,
$$

where $0 \leq m^{k i}, m^{s i} \leq 1, m^{k i}+m^{s i}=1$,

$$
\alpha^{k i} \equiv \frac{k^{i i}+k^{i j}}{k}, \quad \alpha^{s i}=\frac{k^{i i}+k^{j i}}{k}
$$

and $k=k^{i i}+k^{j i}+k^{j j}+k^{i j}$, is the total amount of capital used by the MNC. If region $i$ exclusively uses capital (or property) shares in the apportionment formula, then $m^{k i}=1$, and $\gamma^{i}=\alpha^{k i}$. If it only employs production shares, then $m^{k i}=0$ and $\gamma^{i}=\alpha^{s i}$. A formula that gives positive weights to both factors is represented by $0<m^{k i}<1$.

The formula is applied to the firm's taxable income, which may differ from firm's economic profits due to the imperfect deductibility of capital costs. Next, we establish the specific relationship between taxable income and economic protis. The MNC's total economic profits are

$$
\begin{aligned}
\pi & =\pi^{a}+\pi^{b} \\
& =\left[p\left(k^{a}\right) k^{a}-c^{a}\left(k^{a a}+k^{a b}\right)-\tau k^{a b}\right]+\left[p\left(k^{b}\right) k^{b}-c^{b}\left(k^{b b}+k^{b a}\right)-\tau k^{b a}\right] \\
& =p\left(k^{a}\right)\left(k^{a}\right)+p\left(k^{b}\right) k^{b}-c^{a}\left(k^{a a}+k^{a b}\right)-c^{b}\left(k^{b b}+k^{b a}\right)-\tau\left(k^{a b}+k^{b a}\right),
\end{aligned}
$$

where $\pi^{i}$ is economic profit in country $i$. Total economic profits of the MNC is given by sum of total revenues minus total production costs and total transportation costs. The revenue generated in location $i$ is derived from the units sold by the firm in $i$, which are the sum of the units produced in $i$ and the units produced in $j$ and shipped to $i$. But then the firm 
faces the cost of transporting $k^{j i}$ units from $j$.

The relationship between taxable income and economic profits can be expressed as follows:

$$
\begin{aligned}
\omega & =\omega^{a}+\omega^{b} \\
& =\left[p\left(k^{a}\right) k^{a}-\mu^{a} c^{a}\left(k^{a a}+k^{a b}\right)-\tau k^{a b}\right]+\left[p\left(k^{b}\right) k^{b}-\mu^{b} c^{b}\left(k^{b b}+k^{b a}\right)-\tau k^{b a}\right] \\
& =\pi+\left(1-\mu^{a}\right) c^{a}\left(k^{a a}+k^{a b}\right)+\left(1-\mu^{b}\right) c^{b}\left(k^{b b}+k^{b a}\right),
\end{aligned}
$$

where $\omega^{i}$ is taxable income in country $i$. Country $i$ allows the MNC to deduct a proportion $\mu^{i}$ of capital expenses. Specifically, the MNC can deduct $\mu^{i} c^{i}\left(k^{i i}+k^{i j}\right)$ from its taxable income in $i$. Thus, the firm's total taxable income is given by total economic profits plus two terms that depend on $\mu^{a}$ and $\mu^{b}$ and the capital employed by the MNC. If $\mu^{i}<1$, then as the firm employs more capital in $i$, its taxable income rises as well. On the contrary, when $\mu^{i}>1$, capital employed in $i$ is subsidized, so taxable income declines with higher levels of $k^{i i}$ and $k^{i j}$.

The total taxes paid by the MNC are

$$
T=T^{a}+T^{b}=t^{a} \gamma^{a} \omega+t^{b} \gamma^{b} \omega=\left(t^{a} \gamma^{a}+t^{b} \gamma^{b}\right) \omega,
$$

so after-tax profits $N \equiv \pi-T$ are

$$
\begin{aligned}
N & =\pi-\left(t^{a} \gamma^{a}+t^{b} \gamma^{b}\right) \omega \\
& =\pi(1-\bar{t})-\bar{t}\left(1-\mu^{a}\right) c^{a}\left(k^{a a}+k^{a b}\right)-\bar{t}\left(1-\mu^{b}\right) c^{b}\left(k^{b b}+k^{b a}\right),
\end{aligned}
$$

where $\bar{t}=t^{a} \gamma^{a}+t^{b} \gamma^{b}$ is the effective (total) tax rate faced the firm. 


\subsection{Timing of events}

In what follows, we examine the incentives of domestic governments to choose different FA systems. In doing so, it is assumed that domestic governments decide the formula system non-cooperatively. Additionally, we focus on a partially symmetric equilibrium. Specifically, we assume that all other variables, except $\mu^{a}$ and $\mu^{b}$, are identical, i.e., $\mu^{a}=\mu^{b}=\mu=0, c^{a}=$ $c^{b}=c$, and $t^{a}=t^{b}=t$, and determine which FA systems will be chosen by the domestic governments.

The FA game is modeled as a three-stage game as follows:

1. The governments simultaneously choose $m^{k a}$ and $m^{k b}$;

2. After observing $m^{k a}$ and $m^{k b}$, the MNC decides the capital allocation across countries: $\left\{k^{a a}, k^{b b}, k^{a b}, k^{b a}\right\} ;$

3. Payoffs at each location are determined.

\section{Characterization of the Equilibrium}

In this section, we examine the properties of the equilibrium. We use the notion of Sub-game Perfect Nash equilibrium, which means that we solve the game by backward induction. We begin by studying the response of the MNC in the second stage of the game to different FA systems.

\subsection{Second Stage: The MNC's Problem}

When the MNC produces the good abroad and sell it domestically, it must face a transportation cost. So why would a MNC do so? The answer is that the tax system, in this case the FA system, distorts the firm's decisions regarding where to produce and where to sell. Suppose that the formula used by $a$ weighs capital shares relatively more than the formula employed by $b$ (i.e., $m^{k a}>m^{k b}$ ). Under these conditions, if the firm allocates more capital 
in $a$, taxable income would rise. Thus, the firm has an incentive to shift its production to country $b$. Since $m^{k a}>m^{k b}$ also means that $b$ weighs more heavily the sales proportion of the formula, the MNC may still have incentives to ship and sell part of its production to country $a$. Consequently, when the countries employ different FA methods, the MNC can benefit by changing the allocation of capital across countries. In our model, domestic prices are affected where the MNC changes its capital allocation in response to different tax returns.

The goal of the MNC is to choose the capital allocation $\left\{k^{a a}, k^{b b}, k^{a b}, k^{b a}\right\}$ that maximize total after tax profits $N$. The following Kuhn-Tucker conditions characterize the solution of the previous as a function of the formulas $m^{k a}$ and $m^{k b}$ :

$$
\begin{aligned}
\frac{\partial N}{\partial k^{a a}}= & (1-t)\left(\alpha-2 \beta k^{a}\right)-c+\frac{t \Delta}{k}\left(k^{a b}-k^{b a}\right)\left(\alpha-2 \beta k^{a}-\frac{\omega}{k}\right) \leq 0 ; \\
\frac{\partial N}{\partial k^{b a}}= & (1-t)\left(\alpha-2 \beta k^{a}\right)-c-\tau(1-t)+ \\
& \frac{t \Delta}{k}\left[\left(k^{a b}-k^{b a}\right)\left(\alpha-2 \beta k^{a}-\tau-\frac{\omega}{k}\right)-\omega\right] \leq 0 ; \\
\frac{\partial N}{\partial k^{b b}=} & (1-t)\left(\alpha-2 \beta k^{b}\right)-c+\frac{t \Delta}{k}\left(k^{a b}-k^{b a}\right)\left(\alpha-2 \beta k^{b}-\frac{\omega}{k}\right) \leq 0 ; \\
\frac{\partial N}{\partial k^{a b}}= & (1-t)\left(\alpha-2 \beta k^{b}\right)-c-\tau(1-t)+ \\
& \frac{t \Delta}{k}\left[\left(k^{a b}-k^{b a}\right)\left(\alpha-2 \beta k^{b}-\tau+\frac{\omega}{k}\right)+\omega\right] \leq 0 ;
\end{aligned}
$$

where $\Delta \equiv m^{k b}-m^{k a}$, and the non-negativity and complementary slackness constraints

$$
k^{i j} \geq 0, \quad k^{i j}\left(\partial N / \partial k^{i j}\right)=0, \quad i, j=a, b .
$$

The solutions to the previous problem depends on the value of $\Delta$.

Proposition 1. Suppose that $[\alpha(1-t)-c>0]$ and let

$$
\tilde{\Delta}=\frac{2 \tau(1-t)^{2}}{t[\alpha(1-t)+c]} .
$$


Then, if $-\tilde{\Delta} \leq \Delta \leq \tilde{\Delta}$, then $k^{a a}>0, k^{b b}>0, k^{a b}=k^{b a}=0$

Proof. If $-\tilde{\Delta} \leq \Delta \leq \tilde{\Delta}$, then (4.7) and (4.9) are strictly negative, so that $k^{b a}=k^{a b}=0$ and

$$
k^{a a}=k^{b b}=\tilde{k}=\frac{1}{2 \beta}\left[\frac{\alpha(1-t)-c}{(1-t)}\right]>0 .
$$

Evaluated at $k^{a a}=k^{b b}=\tilde{k}>0$, and $k^{a b}=k^{b a}=0$, equations (4.6) and (4.8) are satisfied with equality. Moreover, (4.7) and (4.9) are respectively

$$
\begin{aligned}
& -\tau(1-t)+t \Delta\left[\frac{\alpha}{2}+\frac{c}{2(1-t)}\right]<0 \\
& -\tau(1-t)-t \Delta\left[\frac{\alpha}{2}+\frac{c}{2(1-t)}\right]<0 .
\end{aligned}
$$

Conditions (4.12) and (4.13) hold when $-\tilde{\Delta}<\Delta<\tilde{\Delta}$. Thus, $k^{a a}=k^{b b}=\tilde{k}, k^{a b}=k^{b a}=0$ is a solution under this condition.

Thus, when the difference between the tax formulas is small enough, specifically, $-\tilde{\Delta}<$ $\Delta \equiv m^{k b}-m^{k a}<\tilde{\Delta}$, then the MNC does not have incentives to produce abroad: the firm's production in country $i$ is entirely directed to satisfy local demand. The reason is that the tax benefits that the firm can obtain from producing elsewhere are not high enough to compensate for the shipping costs.

Note that if $\tilde{\Delta} \geq 1$, then $k^{a a}=k^{b b}=\tilde{k}, k^{a b}=k^{b a}=0$ is the only solution of the MNC's maximization problem since $\Delta$ is between -1 (when $m^{k b}=0$ and $m^{k a}=1$ ) and 1 (when $m^{k b}=1$ and $\left.m^{k a}=0\right)$. If $\tilde{\Delta}<1$, then there are values of $m^{k a}$ and $m^{k b}$ such that $\Delta>\tilde{\Delta}$ or $\Delta<\tilde{\Delta}$.

As $m^{k a}$ increases for a given value of $m^{k b}$ (i.e., $\Delta$ decreases), the benefits of producing (selling) in country $a$ decline (increase). Thus, the MNC shifts production from $a$ to $b$ and ships part of its production to $a$.

Proposition 2. (i) Suppose that $\Delta<-\tilde{\Delta}$. Then, $k^{a a} \geq 0, k^{a b}=0, k^{b a}>0$, and $k^{b b}>0$. (ii) Suppose that $\Delta>\tilde{\Delta}$. Then, $k^{a a}>0, k^{a b}>0, k^{b a}=0$, and $k^{b b} \geq 0$. 
Proof. The system of equations (4.6) - (4.9) evaluated at $k^{a a}=k^{b b}=\tilde{k}$ and $k^{b a}=k^{a b}=0$ gives $\left(\partial N / \partial k^{a a}\right)=\left(\partial N / \partial k^{b b}\right)=0$, and

$$
\begin{aligned}
\frac{\partial N}{\partial k^{b a}} & =-\frac{\Delta t[\alpha(1-t)+c]}{2(1-t)}-(1-t) \tau ; \\
\frac{\partial N}{\partial k^{a b}} & =\frac{\Delta t[\alpha(1-t)+c]}{2(1-t)}-(1-t) \tau .
\end{aligned}
$$

If $\Delta=\tilde{\Delta}+\epsilon$, where $\epsilon>0$, then

$$
\begin{aligned}
\frac{\partial N}{\partial k^{b a}} & =-\frac{\epsilon t[\alpha(1-t)+c]}{2(1-t)}-2(1-t) \tau<0 \\
\frac{\partial N}{\partial k^{a b}} & =\frac{\epsilon t[\alpha(1-t)+c]}{2(1-t)}>0 .
\end{aligned}
$$

Equation (4.16) implies that $k^{b a}=0$, while from (4.17) states that $k^{a b}$ should be raised. An analogous derivation can be followed to conclude that $k^{a b}=0$ and $k^{a b}$ should be increased when $\Delta=-\tilde{\Delta}-\epsilon$.

It can be concluded that beginning with low values of $m^{k a}$ (or high positive values of $\Delta$ ), as $m^{k a}$ increases the following solutions will be obtained:

Case 1: $k^{a a}>0, k^{b a}=0, k^{a b}>0, k^{b b}=0 ;$

Case 2: $k^{a a}>0, k^{b a}=0, k^{a b}=, k^{b b}>0$;

Case 3: $k^{a a}>0, k^{b a}=0, k^{a b}=0, k^{b b}>0$;

Case 4: $k^{a a}>0, k^{b a}>0, k^{a b}=0, k^{b b}>0$;

Case $5: k^{a a}=0, k^{b a}>0, k^{a b}>0, k^{b b}>0$;

We construct in the next section a numerical example to ilustrate the previous results.

\subsection{Numerical Example}

The numerical example examines the solution of the MNC for different FA systems chosen by the governments in $a$ and $b$. The example use the following parameter values: $\alpha=10, \beta=$ $2, c=4, \tau=1$, and $t=0.30$. The values of these exogenously given parameters decide 
the value of $\tilde{\Delta}$. As we have seen in the propositions before, the value of $\tilde{\Delta}$ relative to $\Delta$ decides the different cases of capital allocation in the two locations. This value of $\tilde{\Delta}$ is very crucial. From the particular values of the exogenously given parameters, it is implied that $\tilde{\Delta}=0.3$. As $m^{k a}$ and $m^{k b}$ change and, thus, $\Delta$ changes, we have the different cases of capital allocation by the MNC. In the tables [see tables (4.1),(4.2) and (4.3)], we consider values of $m^{k a}$ and $m^{k b}$ ranging from 0 to 1 . The objective is to investigate the impact of different FA systems on the total amount of capital allocated in the two locations, the amount of production shifted from one location to the other, the amount of tax revenues generated, the amount of consumer surplus, the prices of goods in the two locations and the net profits of MNC. The tables show the values of these variables as a function of the FA chosen in country $a$ for several different fixed values of $m^{k b}$. Since the countries are symmetric, with the exception of the FA system, similar results hold for country $b$. Most importantly, as we can see form the table, that as the capital allocations change, the price of the good produced in a particular location changes. As we will see later that the different Nash Equilibria are also conditioned on the particular value of $\tilde{\Delta}$. For certain range of values of $\Delta$, the firms always produce in respective locations and, thus, we have Case 3. Again, for certain values of $\Delta$, the firm ends up producing only in a particular location.

\subsection{First Stage: The Government's Problem}

At the first stage of the game, the governments simultaneously decide their respective FA systems anticipating the MNC's reaction in the second stage. It is assumed that the government implements domestically the policy that maximizes the welfare of certain political groups. Specifically, the government of country $i$ may wish to implement a formula that maximizes the well-being of domestic consumers. In this case, the government would chooses the value of $m^{k i}$ that maximizes the consumer surplus in $i$, or $C S^{i}$. The government may wish to choose a formula that maximizes the size of the government, in which case the government would implement a formula that maximizes total tax revenue in country $i, T^{i}$. Finally, the 
government may wish to maximize the well-being of the MNC and implement a formula that maximizes total net profits $N$.

Considering the previous alternatives, we assume that the government in $i$ chooses the FA system $m^{k i}$ that maximizes the objective function

$$
W^{i}=\theta_{C S}^{i} C S^{i}+\theta_{T}^{i} T^{i}+\theta_{M}^{i} N
$$

where $\theta_{C S}^{i}+\theta_{T}^{i}+\theta_{M}^{i}=1$. The parameters $\theta_{h}^{i}, h=C S, T, M$ represent the political weight of group $j$ on government $i$ 's objective function. Different FA would be used by the domestic government depending on the value of the parameter $\theta_{j}^{i}$.

The following section characterizes the equilibrium achieved for different government's objectives using the numerical example developed earlier.

\section{Results}

In this section, we summarize the Sub-game Perfect Nash Equilibria that would be reached under different values of $\theta_{j}^{i}{ }^{2}$ These are all derived based on the standard assumption that the government in the two locations act in a non co-operative way. The equilibrium conditions change as the welfare maximizing objectives of the domestic government changes. We consider three cases: (i) $\theta_{T}^{i}=1$, (ii) $\theta_{C S}^{i}=1$, and (iii) $\theta_{M}^{i}=1$. Figures $* * *$ summarize the results from the previous table focusing on the consumer surplus, tax revenue, and the MNC's net profits.

\subsection{Case (i): $\theta_{T}^{i}=1$}

Suppose that the government wants to maximize tax revenues in location $a$, i.e., $\theta_{T}^{i}=1$. Figure (4.1) shows that when country $b$ chooses low values of $m^{k b}=0$, then $a$ 's best response

\footnotetext{
${ }^{2}$ Throughout the analysis we assume that governments of both countries have the same objectives, i.e., $\theta_{h}^{i}=\theta_{h}^{j}$.
} 
is to choose $m^{k a}=0$ as well. A similar reasoning holds for country $b$. In other words, when governments want to maximize domestic tax revenue, the equilibrium FA system would give full weight to sales portion of the formula. Actually, other than the above mentioned case, there can be a range of values over which the Nash Equilibrium can be true. The numerical examples states that $\left\{m^{k a} \leq 0.3, m^{k b} \leq 0.3\right\}$ are all Nash Equilibria. Thus, as long as the tax on capital share in each location is low, the equilibria conditions are satisfied. Here, we have $\Delta$ lying between -0.3 to 0.3 . So $-\tilde{\Delta}<\Delta \equiv m^{k b}-m^{k a}<\tilde{\Delta}$ is satisfied. The MNC does not have incentives to produce abroad: the firm's production in country $i$ is entirely directed to satisfy local demand. Since the government's objective is to maximize tax revenues, the MNC firm does not really benefit by producing abroad. The MNC only decides to produce abroad when the benefits from tax incentives in one location (low weight on capital shares) outweighs the cost of transporting the good between the two locations. In this case, the tax on capital share is low in both locations and, thus, there is no incentive to produce abroad. So only Case 3 is satisfied. Also, after-tax profits are maximized for MNC in the range $\left\{m^{k a} \leq 0.3, m^{k b} \leq 0.3\right\}$. Also, the total capital allocation by the MNC is minimum for the range values which satisfy Nash Equilibria conditions. Thus, with minimum capital allocaion, the after-tax profits are still maximized.

\subsection{Case (ii): $\theta_{C S}^{i}=1$}

Next, suppose that the government wants to maximize consumer surplus in location $a$, i.e., $\theta_{C S}^{i}=1$. Figure (4.2) shows that when country $b$ chooses high values of $m^{k b}=1$, then $a$ 's best response is to choose $m^{k a}=1$ as well. The same argument holds for country $b$. The equilibrium FA system would give full weight to the capital portion of the formula when governments want to maximize consumer surplus. The mentioned case is a subset of some other cases. There can be a range of values over which Nash Equilibrium can be true. The numerical examples states that $\left\{m^{k a} \geq 0.7, m^{k b} \geq 0.7\right\}$ are all Nash Equilibria. Thus, the equilibria conditions will be satisfied as long as the tax on sales share in each location is 
low. Similarly here also $\Delta$ lies between -0.3 and 0.3 . Thus, $-\tilde{\Delta}<\Delta \equiv m^{k b}-m^{k a}<\tilde{\Delta}$ is again satisfied. Again, the MNC has no incentive to produce abroad. The tax on capital share, this case, is high in both locations, and, thus, it is most efficient for the MNC to produce in the respective locations. Here, again only Case 3 is satisfied. Again, for the range $\left\{m^{k a} \geq 0.7, m^{k b} \geq 0.7\right\}$, the capital allocation is minimum and after-tax profits are maximized.

\subsection{Case (iii): $\theta_{N}^{i}=1$}

Finally, suppose that the government wants to maximize the sum of consumer surplus in location $a$, i.e., $\theta_{C S}^{i}=1$. Figure (4.3) shows that when country $b$ chooses high values of $m^{k b}=1$, then $a$ 's best response is to choose $m^{k a}=1$ as well. Again, when country $b$ chooses low values of $m^{k b}=0$, then $a$ 's best response is to choose $m^{k a}=0$ as well. A similar reasoning holds for country $b$. In other words, in this case, the Nash Equilibrium can be true over the entire range of values $\left\{0 \leq m^{k a} \leq 1,0 \leq m^{k b} \leq 1\right\}$. This is the case where the MNC has the incentive to produce abroad. Here, both the conditions $\Delta<-\tilde{\Delta}$ or $\Delta>\tilde{\Delta}$ are possible. Intuitively, if the tax on capital share is low in $a$, then the MNC has the incentive to shift production from $a$ to $b$.

\section{Conclusion}

In this paper, we explore the impacts on domestic welfare when the multinational firm is taxed based on formula apportionment. The government has the incentive to maximize consumer surplus, tax revenues or after tax profits of the multinational firm. The formula chosen by the government based on its objectives will provide incentive to the MNC to decide on its activities in a given location. The papers makes an important contribution to the literature because it explores the corporate taxation policies of multinationals by using a political economy framework. The incentives of the multinational firm to choose a certain 
formula of taxation will depend on the actions taken by the local government to improve upon domestic welfare of a nation. Further, the model also points out that the formula chosen to tax a MNC in a particular location has an impact on the pricing strategy of the MNC. As firms change their capital and sales shares in reaction to the policies adopted by the government, it has its impact on the price of domestic goods.

In the future, the model aims to investigate the different FA systems when we have a MNC firm and a domestic firm in each of the two locations. The government, in such a case, will have an added incentive of maximizing the welfare of domestic capitalists as well. Also, the model wishes to explore the outcomes if governments have conflicting objectives in the different locations. For example, while the government in location $a$ may wish to maximize tax revenues, the objective of the government in location $b$ is to maximize consumer surplus. Finally, we want to analyze the outcomes when the country chooses the separate accounting tax system instead of formula apportionment. 
Table 4.1: For $m^{k b}=0$

\begin{tabular}{l|rrrrr|rr|rrr|rr|r}
\hline$m^{k a}$ & $k^{a a}$ & $k^{a b}$ & $k^{b a}$ & $k^{b b}$ & $k$ & $p\left(k^{a}\right)$ & $p\left(k^{b}\right)$ & $T^{a}$ & $T^{b}$ & $T$ & $C S^{a}$ & $C S^{b}$ & $N$ \\
\hline 0.00 & 1.07 & 0.00 & 0.00 & 1.07 & 2.14 & 7.86 & 7.86 & 2.53 & 2.53 & 5.05 & 1.15 & 1.15 & 8.27 \\
0.10 & 1.07 & 0.00 & 0.00 & 1.07 & 2.14 & 7.86 & 7.86 & 2.53 & 2.53 & 5.05 & 1.15 & 1.15 & 8.27 \\
0.20 & 1.07 & 0.00 & 0.00 & 1.07 & 2.14 & 7.86 & 7.86 & 2.53 & 2.53 & 5.05 & 1.15 & 1.15 & 8.27 \\
0.30 & 0.98 & 0.00 & 0.09 & 1.07 & 2.14 & 7.86 & 7.86 & 2.44 & 2.51 & 4.95 & 1.14 & 1.14 & 8.16 \\
0.40 & 0.00 & 0.00 & 1.08 & 1.04 & 2.12 & 7.84 & 7.92 & 1.43 & 2.30 & 3.73 & 1.16 & 1.08 & 7.14 \\
0.50 & 0.00 & 0.00 & 1.13 & 1.03 & 2.16 & 7.73 & 7.94 & 1.24 & 2.26 & 3.50 & 1.28 & 1.06 & 7.16 \\
0.60 & 0.00 & 0.00 & 1.18 & 1.03 & 2.21 & 7.63 & 7.95 & 1.03 & 2.23 & 3.26 & 1.40 & 1.05 & 7.17 \\
0.70 & 0.00 & 0.00 & 1.23 & 1.02 & 2.25 & 7.54 & 7.96 & 0.80 & 2.20 & 2.99 & 1.52 & 1.04 & 7.16 \\
0.80 & 0.00 & 0.00 & 1.28 & 1.02 & 2.29 & 7.45 & 7.97 & 0.55 & 2.17 & 2.71 & 1.63 & 1.03 & 7.15 \\
0.90 & 0.00 & 0.00 & 1.32 & 1.01 & 2.33 & 7.36 & 7.98 & 0.28 & 2.14 & 2.42 & 1.74 & 1.02 & 7.14 \\
1.00 & 0.00 & 0.00 & 1.36 & 1.01 & 2.37 & 7.28 & 7.98 & 0.00 & 2.12 & 2.12 & 1.85 & 1.02 & 7.12 \\
\hline
\end{tabular}

Table 4.2: For $m^{k b}=0.5$

\begin{tabular}{r|rrrrr|rr|rrr|rr|r}
\hline$m^{k a}$ & $k^{a a}$ & $k^{a b}$ & $k^{b a}$ & $k^{b b}$ & $k$ & $p\left(k^{a}\right)$ & $p\left(k^{b}\right)$ & $T^{a}$ & $T^{b}$ & $T$ & $C S^{a}$ & $C S^{b}$ & $N$ \\
\hline 0.00 & 1.03 & 1.13 & 0.00 & 0.00 & 2.16 & 7.94 & 7.73 & 2.26 & 1.24 & 3.50 & 1.06 & 1.28 & 7.16 \\
0.10 & 1.04 & 1.08 & 0.00 & 0.00 & 2.12 & 7.92 & 7.84 & 2.53 & 1.19 & 3.73 & 1.08 & 1.16 & 7.14 \\
0.20 & 1.07 & 0.09 & 0.00 & 0.98 & 2.14 & 7.86 & 7.86 & 2.55 & 2.40 & 4.95 & 1.14 & 1.14 & 8.16 \\
0.30 & 1.07 & 0.00 & 0.00 & 1.07 & 2.14 & 7.86 & 7.86 & 2.53 & 2.53 & 5.05 & 1.15 & 1.15 & 8.27 \\
0.40 & 1.07 & 0.00 & 0.00 & 1.07 & 2.14 & 7.86 & 7.86 & 2.53 & 2.53 & 5.05 & 1.15 & 1.15 & 8.27 \\
0.50 & 1.07 & 0.00 & 0.00 & 1.07 & 2.14 & 7.86 & 7.86 & 2.53 & 2.53 & 5.05 & 1.15 & 1.15 & 8.27 \\
0.60 & 1.07 & 0.00 & 0.00 & 1.07 & 2.14 & 7.86 & 7.86 & 2.53 & 2.53 & 5.05 & 1.15 & 1.15 & 8.27 \\
0.70 & 1.07 & 0.00 & 0.00 & 1.07 & 2.14 & 7.86 & 7.86 & 2.53 & 2.53 & 5.05 & 1.15 & 1.15 & 8.27 \\
0.80 & 0.98 & 0.00 & 0.09 & 1.07 & 2.14 & 7.86 & 7.86 & 2.34 & 2.61 & 4.95 & 1.14 & 1.14 & 8.16 \\
0.90 & 0.00 & 0.00 & 1.08 & 1.04 & 2.12 & 7.84 & 7.92 & 0.24 & 3.49 & 3.73 & 1.16 & 1.08 & 7.14 \\
1.00 & 0.00 & 0.00 & 1.13 & 1.03 & 2.16 & 7.73 & 7.94 & 0.00 & 3.50 & 3.50 & 1.28 & 1.06 & 7.16 \\
\hline
\end{tabular}

Table 4.3: For $m^{k b}=1$

\begin{tabular}{r|rrrrr|rr|rrr|rr|r}
\hline$m^{k a}$ & $k^{a a}$ & $k^{a b}$ & $k^{b a}$ & $k^{b b}$ & $k$ & $p\left(k^{a}\right)$ & $p\left(k^{b}\right)$ & $T^{a}$ & $T^{b}$ & $T$ & $C S^{a}$ & $C S^{b}$ & $N$ \\
0.00 & 1.01 & 1.36 & 0.00 & 0.00 & 2.37 & 7.98 & 7.28 & 2.12 & 0.00 & 2.12 & 1.02 & 1.85 & 7.12 \\
0.10 & 1.01 & 1.32 & 0.00 & 0.00 & 2.33 & 7.98 & 7.36 & 2.42 & 0.00 & 2.42 & 1.02 & 1.74 & 7.14 \\
0.20 & 1.02 & 1.28 & 0.00 & 0.00 & 2.29 & 7.97 & 7.45 & 2.71 & 0.00 & 2.71 & 1.03 & 1.63 & 7.15 \\
0.30 & 1.02 & 1.23 & 0.00 & 0.00 & 2.25 & 7.96 & 7.54 & 2.99 & 0.00 & 2.99 & 1.04 & 1.52 & 7.16 \\
0.40 & 1.03 & 1.18 & 0.00 & 0.00 & 2.21 & 7.95 & 7.63 & 3.26 & 0.00 & 3.26 & 1.05 & 1.40 & 7.17 \\
0.50 & 1.03 & 1.13 & 0.00 & 0.00 & 2.16 & 7.94 & 7.73 & 3.50 & 0.00 & 3.50 & 1.06 & 1.28 & 7.16 \\
0.60 & 1.04 & 1.08 & 0.00 & 0.00 & 2.12 & 7.92 & 7.84 & 3.73 & 0.00 & 3.73 & 1.08 & 1.16 & 7.14 \\
0.70 & 1.07 & 0.09 & 0.00 & 0.98 & 2.14 & 7.86 & 7.86 & 2.66 & 2.29 & 4.95 & 1.14 & 1.14 & 8.16 \\
0.80 & 1.07 & 0.00 & 0.00 & 1.07 & 2.14 & 7.86 & 7.86 & 2.53 & 2.53 & 5.05 & 1.15 & 1.15 & 8.27 \\
0.90 & 1.07 & 0.00 & 0.00 & 1.07 & 2.14 & 7.86 & 7.86 & 2.53 & 2.53 & 5.05 & 1.15 & 1.15 & 8.27 \\
1.00 & 1.07 & 0.00 & 0.00 & 1.07 & 2.14 & 7.86 & 7.86 & 2.53 & 2.53 & 5.05 & 1.15 & 1.15 & 8.27 \\
\hline
\end{tabular}


Figure 4.1: Tax Revenues in $a$ as a function of $m^{k a}$ for different values of $m^{k b}$

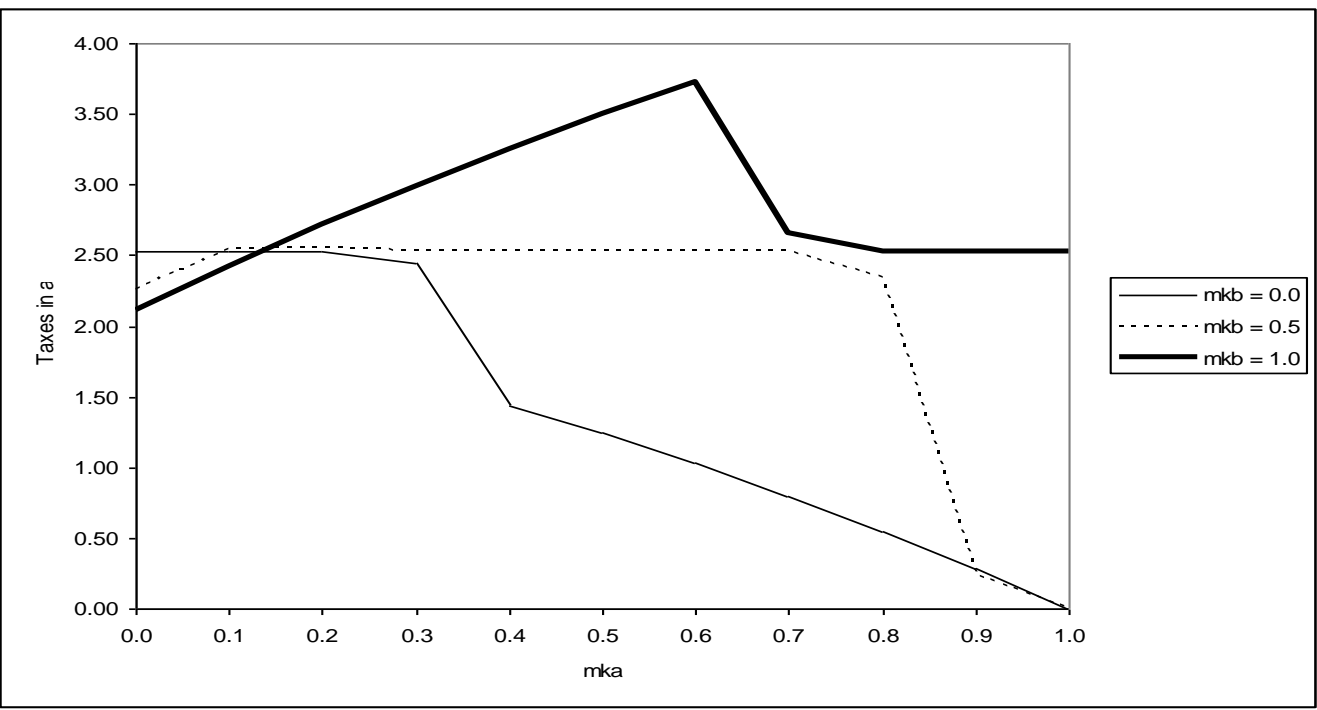


Figure 4.2: Consumer Surplus in $a$ as a function of $m^{k a}$ for different values of $m^{k b}$

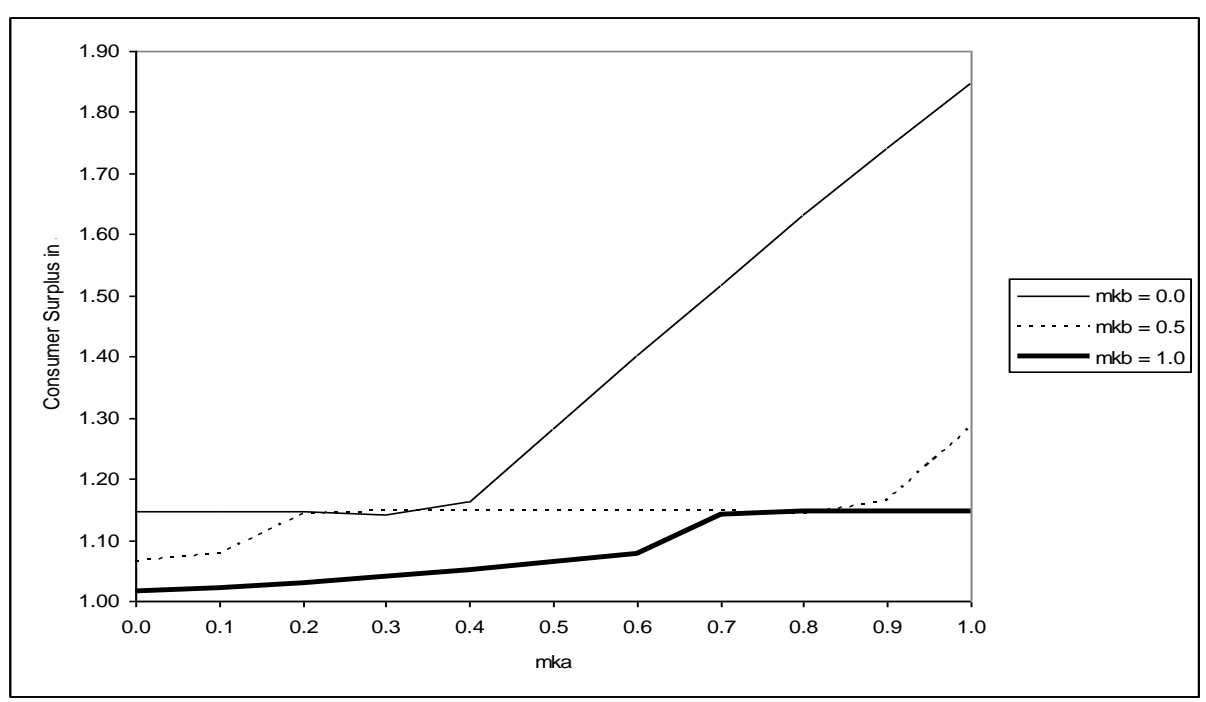


Figure 4.3: After-Tax profits in $a$ as a function of $m^{k a}$ for different values of $m^{k b}$

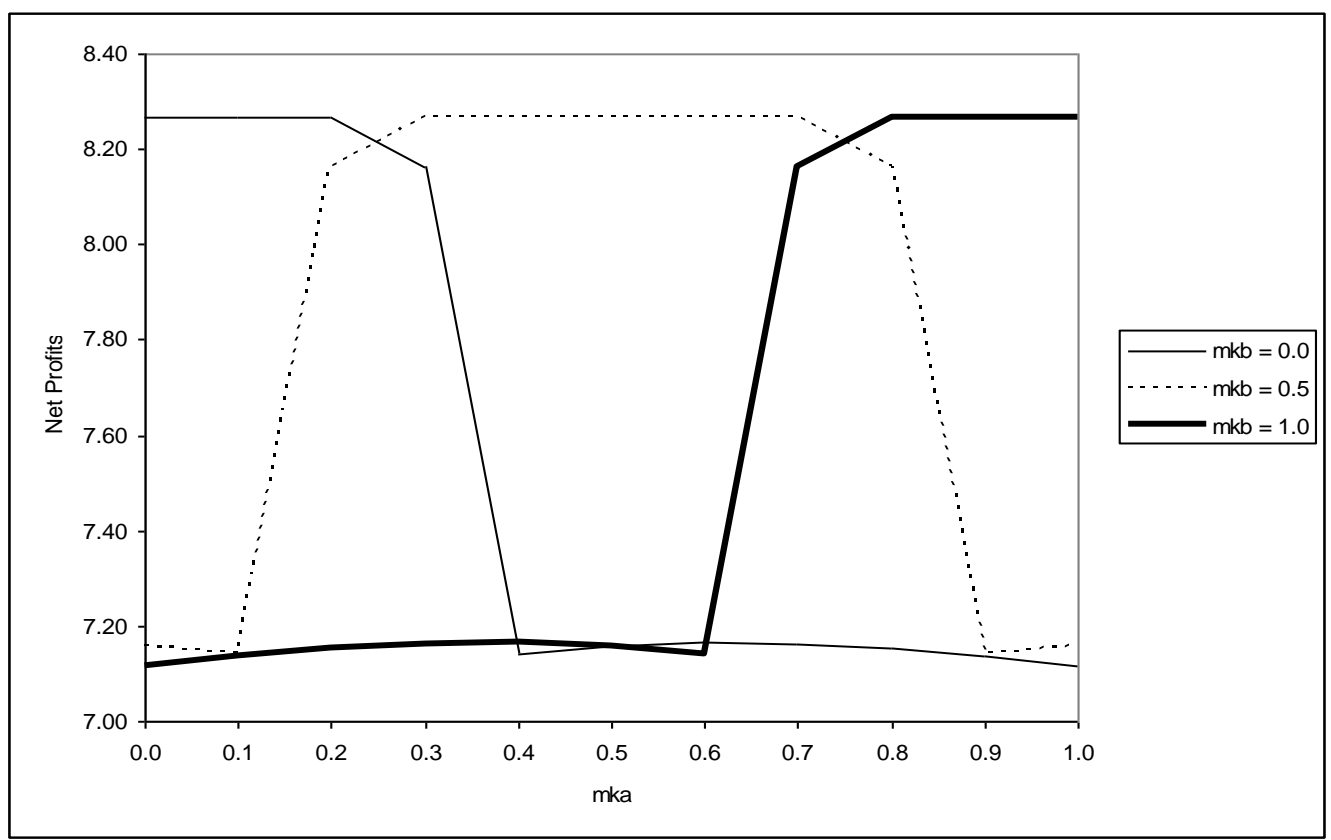




\section{Chapter 5}

\section{Conclusion}

My dissertation essays explore the role of political economy in the context of different types of capital flows. The capital flows can be in terms of asset return of firms, foreign aid allocation to the developing world or the allocation of capital by multinational firms in different locations. The general conclusion that can be drawn from the three essays is that political economy plays a crucial role in the different types of capital flows as discussed in the three essays.

Specifically, the first essay paper stresses the role of political institutions in the development of stock markets in emerging markets. Enhancement of political institutions or more democratic institutions implies more political stability due to the inherent link between them. Such economies create investor friendly environments for the investors,an environ-

ment with secured property rights, lower risks of expropriation by the government and well developed capital markets and, thus, the investors can invest under low-risk conditions. The results suggest that better political institutions have a negative relationship with average asset return conditional on the fact that the nationalization of assets has not occurred in the sample set. Firms in autocratic regimes have higher average returns that exceed the required returns which is consistent with the fact that autocratic institutions are more prone to political and financial risks. In CAPM framework over long enough period of time average 
returns should be equal to the required returns. The fact that the average returns are higher than the required returns in autocratic countries can partly be explained by the fact that the nationalization of the assets, for which investors require insurance premium, has not yet occurred in my sample.

The primary conclusion of the second essay implies that aid does not have the kind of institutional-trajectory reversing power for democracies or dictatorships. Instead, we find evidence for a more modest impact of aid on recipients' political institutions, which amplifies or reinforces the trajectory of political institutions that developing nations are already on. Aid makes virtually all already democratic countries more democratic and virtually all already dictatorial countries stronger dictatorships, but it does not fundamentally affect the underlying regime type of developing nations. Our results also suggest a possible mechanism at work that helps to explain Burnside and Dollar's (2000) finding that aid promotes growth in countries that pursue good policies, but fails to do so in countries that do not. To the extent that because of their stronger constraints on executive power democracies tend to pursue better economic policies than dictatorships, when democracies receive foreign aid they become more democratic, leading to the adoption of better policies, which in turn leads to higher economic growth. Conversely, when dictatorships receive aid they become more dictatorial, preventing the adoption of better policies, which in turn prevents increases in economic growth. Finally, our results suggest that aid exerts almost no impact on the political institutions of recipient countries with undecided regimes. 


\section{Bibliography}

Acemoglu, Daren, S.Johnson, and J.Robinson, "Colonial origins of comparative development:An empirical investigation," American Economic Review, 2001, 91 (5), 1369-1401.

, and , "Reversal of Fortune: Geography and Institutions in the Making of the Modern World Income Distribution," Quarterly Journal of Economics, 2002, 107 (4), 1231-1294.

Alder, M. and B. Dumas, "International portfolio choice and corporation finance:A synthesis," Journal of Finance, 1983, 38, 925-984.

Anand, B. and R. Sansing, "The weighting game: formula apportionment as an instrument of public policy," National Tax Journal, 2000, 53, 183-199.

Barro, Robert, "Economic Growth in a Cross Section of Countries," Quarterly Journal of Economics, 1991, 106 (2), 407-443.

, "Democracy and Growth," Journal of Economic Growth, 1996, 1 (1), 1-27.

Bauer, Peter T., From Subsistence to Exchange and Other Essays 2000.

Baum, A. M. and Lake A. David, "The Political Economy of Growth: Democracy and Human Capital," American Journal of Political Science, 2003, 47 (2), 333-347.

Beck, Thorsten and Ross Levine, "Legal Institutions and Financial Development," NBER Working Paper, 2003.

, Asli Demirguc-Kunt, and Ross Levine, "A New Database on Financial Development and Structure," World Bank Economic Review, 2003, 14 (3), 597-605.

, Ross Levine, and N. Loayza, "Financial Development and the Sources of Growth," Journal of Financial Economics, 2000, 58 (1-2), 261-300.

Besley, T., "Property Rights and Investment Incentives: Theory and Evidence from Ghana," Journal of Political Economy, 1995, 103, 903-937.

Birger, Nilsson, "International Asset Pricing and the benefits and the Benefits from World Market Diversification," Working Paper Series, 2002, 8 (3), 773-816. 
Black, Fischer, Michael C. Jensen, and Myron Scholes, "The Capital Asset Pricing Model: Some Empirical Tests," M.C. Jensen (ed.), Studies in the Theory of Capital Markets (New York: Praeger), 1972, pp. 79-121.

Brutigam, Deborah A. and Stephen Knack, "Foreign Aid, Institutions and Governance in Sub-Saharan Africa," Economic Development and Cultural Change, 2004, 52, 255-285.

Burnside, Craig and David Dollar, "Aid, Policies, and Growth," American Economic Review, 2000, 90, 847-868.

and __ "Aid, Policies, and Growth: Revisiting the Evidence," World Bank Policy Research Working Paper Series No.3251, 2004.

Busse, Mathias, "Democracy and FDI," HWWA Discussion Paper, 2003, (220).

Chang, Jow-Ran, Errunza Vihang, Hogan Ked, and Mao-Wei Hung, "An Intertemporal International Asset Pricing Model: Theory and Empirical Evidence," European Financial Management, 2005, 11 (2), 173-194.

Clague, C., C.P. Keefer, S. Knack, and M. Olson, "Property and Contract Rights under Democracy and Dictatorship," Journal of Economic Growth, 1996, 1, 243-276.

Clark, E., "Valuing Political Risk," Journal of International Money and Finance, 1997, 16, 477-490.

"Political risk in Hong Kong and Taiwan: Pricing the China Factor," Journal of Economic Integration, 1998, 13 (2), 276-291.

Clark, Ephraim and Radu Tunaru, "Emerging Markets: Stock Market Investing with Political Risk," Cass Business School Research Paper, 2003.

Cochrane, John H., "Production-Based Asset Pricing and the Link between Stock Returns and Economic Fluctuations," Journal of Finance, 1991, 46, 209-237.

, "A Cross-Sectional Test of an Investment-Based Asset Pricing Model," Journal of Political Economy, 1996, 104 (3), 572-621.

DeMooij, Ruud and Sjef Ederveen, "Taxation and Foreign Direct Investment: A Synthesis of Empirical Research," International Tax and Public Finance, 2003, 10 (6), 673-93.

Devereux, M. P. and R. Griffith, "Taxes and the Location of Production: Evidence from a Panel of US multinationals," Journal of Public Economics, 1998, 68, 335-367.

Djankov, Simeon, Jose Garcia Montalvo, and Marta Reynal-Querol, "The Curse of Aid," Journal of Economic Growth, 2008, 13, 169-194.

Dumas, B. and B. Solnik, "The World Price of Foreign Exchange Risk," Journal of Finance, 1995, 50 (2), 445-479. 
Easterly, William and Ross Levine, "Africa's Growth Tragedy: Policies and Ethnic Divisions," Quarterly Journal of Economics, 2001, 112, 1203-1250.

, and David Roodman, "Aid, Policies, and Growth:Comment," American Economic Review, 2001, 94, 744-780.

Eggert, W. and G. Schjelderup, "Symmetric Tax Competition under Formula Apportionment," Journal of Public Economic Theory, 2003, 5, 439-446.

and __ , "Corporate Tax Systems and Cross Country Profit Shifting: Formula Apportionment versus Separate Accounting," Working Paper, 2005.

Fama, E. and J. McBeth, "Risk, return and equilibrium: Empirical tests," Journal of Political Economy, 1973, 81, 607-636.

and K. French, "The cross-section of expected stock returns," Journal of Finance, 1992, 47, 427-465.

and , "Common risk factors in the returns on stocks and bonds," Journal of Financial Economics, 1993, 33, 3-56.

Friedman, Milton, "Capitalism and Freedom," University of Chicago Press, 1962.

Funke, Norbert, "Stock Market Developments and Private Consumer Spending in Emerging Markets," IMF working paper, 2002.

Gerard, M. and J. M. Weiner, "Cross-Border Loss Offset and Formulary Apprtionment: How Do They Affect Multijurisdictional Firm Investment Spending and Interjurisdictional Tax Competitio?," CESifo Working Paper NO. 1004, 2003.

Giovannini, A. and P. Jorion, "The time-variation of risk and return in the foreign exchange and stock market," Journal of Finance, 1989, 44, 307-325.

Glaeser, Edward L., Giacomo A. M. Ponzetto, and Andrei Shleifer, "Does Democracy Need Education?," Journal of Economic Growth, 2007.

, Rafael La Porta, Florencio Lopez de Silanes, and Andrei Shleifer, "Do Institutions Cause Growth?," Journal of Economic Growth, 2004, 9, 271-303.

Gordon, R. and J. Wilson, "An Examination of Multijurisdictional Corporate Income Taxation under Formula Apportionment," Econometrica, 1986, pp. 1357-1374.

Harvey, C., "Predictable risk and returns in emerging markets," Review of Financial Studies, 1995, 8 (3), 773-816.

Huang, Yongfu, "Will political liberalisation bring about financial development?," Working Paper, 2005.

and Jonathan Temple, "Does External Trade promote Finanical Development?," CEPR Discussion Paper No. 5150, 2005. 
Jorion, P., "The Pricing of Exchange Rate Risk in the Stock Market," Journal of Financial and Quantitative Analysis, 1991, 26 (3), 361-376.

Kan, Raymond and Zhang Chu, "Two-Pass Tests of Asset Pricing Models with Useless Factors," The Journal of Finance, 1996, 54 (1), 203-235.

K.Gupta, Dipak, M. Madhavan, and A. Blee, "Democracy, Economic Growth and Political Instability: An Integrated Perspective," Journal of Socio-Economics, 1997, 27 (5), 588-611.

Knack, Stephen, "Aid Dependence and the Quality of Governance: Cross-Country Empirical Tests," Southern Economic Journal, 2001, 68, 310-329.

, "Does Foreign Aid Promote Democracy?," International Studies Quarterly, 2004, 48, 251-266.

and Philip Keefer, "Institutions and Economic Performance: Cross-Country Tests Using Alternative Institutional Measures," Economics and Politics, 1995, 7 (3), $207-227$.

Leite, Carlos and Jens Weidmann, "Does Mother Nature Corrupt? Natural Resources, Corruption, and Economic Growth," IMF Working Paper 99/85, 1999.

L'Her, Jean Francois and Jean-Marc Suret, "Liberalization, Political Risk and Stock Market Returns in Emerging Markets," Working Paper, 1997.

Lipset, Seymour Martin, "Some Social Requisites for Democracy: Economic Development and Political Legitimacy," American Political Science Review, 1959, 53, 69-105.

Minier, J. A., "Democracy and Growth: Alternative Approaches," Journal of Economic Growth, 1998, 3 (3), 241-266.

Mintz, J., "Corporate tax harmonization in Europe: Its all about compliance.," International Tax and Public Finance, 2004, 11, 221-224.

Nielsen, S., P. Raimondos-Mller, and G. Schjelderup, "Company Taxation and Tax Spillovers: Separate Accounting versus Formula Apportionment," Working Paper, 2002.

and "Formula Apportionment and Transfer Pricing under Oligopolistic Competition," Journal of Public Economic Theory, 2003, 5, 419-437.

North, Douglas, "Institutions," Journal of Economic Perspective, 1991, 5 (1), 97-112.

and Barry Weingast, "Constitutions and Commitment: the Evolution of Institutions Governing Public Choice in Seventeenth Century England," Journal of Economic History, 1989, 49 (4).

Olson, M., "Dictatorship, democracy and development," American Political Science Review, 1993, 87, 567-76. 
Perotti, Enrico C. and Pieter VanOijen, "Privatization, Political Risk and Stock Market Development in Emerging Economies in Emerging Economies," Tinbergen Institute Discussion Papers, 1999.

Persson, Torsten, "Forms of Democracy, Policy and Economic Development," NBER Working Paper, 2005, (11171).

Phylaktis, Kate and Fabiola Ravazzolo, "Stock Prices and Exchange Rate Regimes," Emerging Market Review, 2004, 5, 317-339.

Pinto, Santiago M., "Corporate profit tax, capital mobility, and formula apportionment," Journal of Public Economics, 2007, 76, 76-102.

Poirson, H., "Essais en Economie de la Croissance et du dveloppement," Thse de Doctorat, Ecole des Hautes Etudes en Sciences Sociales, 1998.

Rajan, R. and L. Zingales, "The Great Reversals: The Politics of Financial Development in the Twentieth Century," Journal of Financial Economics, 2003, 69, 5-50.

Rajan, Raghuram and Arvind Subramanian, "What Undermines Aid's Impact on Growth?," IMF Working Paper 05/126, 2005.

and _ "Some Social Requisites for Democracy: Economic Development and Political Legitimacy," American Political Science Review, 2007, 53, 69-105.

Robbock, Stefan H. and K. Simonds, International Business and Multinational Enterprise 1973.

Sachs, Jeffrey D. and Andrew M. Warner, "Natural Resource Abundance and Economic Growth," NBER Working Paper No. 5398, 1997.

Santis, G. De and B.Gerard, "How big is the premium for currency risk?," Journal of Financial Economics, 1998, 49, 375-412.

Srenson, P., "Company tax reform in the European Union," International Tax and Public Finance, 2004, 11, 91-115.

Svensson, Jakob, "Aid, Growth and Democracy," Economics and Politics, 1999, 11, 275297. $437-461$.

Tavares, J. and R. Wacziarg, "How democracy affects growth," European Economic Review, 2001, 45 (8), 1341-78.

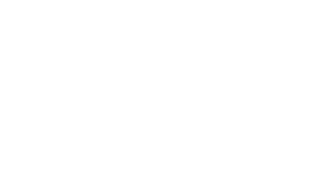

